\title{
Academia, Conflicto Armado y Paz en Colombia: Un Acercamiento desde la Geopolítica del Conocimiento*
}

\author{
María Antonieta Corcione-Nieto ${ }^{1}$ \\ ${ }^{1} \mathrm{PhD}$ en Antropología, Universidad de los Andes, Colombia. Magíster en Biología Humana, Universidad \\ Autónoma de Barcelona. Antropóloga de la Universidad de los Andes. Escuela de Aviación del Ejército, \\ Bogotá D.C., Colombia. \\ E-mail: mariacorcionenieto@cedoc.edu.co
}

Andrés Eduardo Fernández-Osorio ${ }^{2}$

${ }^{2} \mathrm{PhD}$ en Derecho y Ciencia Política, Universidad de Barcelona, España. Magister en Estudios de Defensa, King's College London, Reino Unido. Magister en Economía, Estado y Sociedad: Política y Seguridad, University College London, Reino Unido. Magister en Relaciones Internacionales, Escuela Superior de Economía, Federación de Rusia. Escuela Superior de Guerra "General Rafael Reyes Prieto", Bogotá D.C., Colombia. E-mail: andres.fernandez@buzonejercito.mil.co

\section{Leidy Johana Cabrera-Cabrera}

${ }^{3}$ Magíster y especialista en Docencia e Investigación Universitaria, Universidad Sergio Arboleda. Trabajadora social de la Universidad de La Salle. Escuela Militar de Cadetes "General José María Córdova", Bogotá D.C., Colombia.

E-mail: leidy.cabrera@esmic.edu.co

\section{INTRODUCCIÓN}

Colombia es un país históricamente afectado por un complejo conflicto armado interno, en el cual diversos factores se han sumado para dar origen a una intrincada multiplicidad de violencias. Individualidades, percepciones grupales y construcciones sociales se han visto afectadas por diversos altibajos en la búsqueda de la paz, lo cual ha dado lugar a una gran cantidad de aportes y reflexiones que

*Este artículo presenta de forma conjunta los resultados de proyectos de investigación en colaboración entre tres instituciones: 1) La Escuela Superior de Guerra "General Rafael Reyes Prieto" y su Grupo de Investigación "Centro de Gravedad" categorizado en A1 por Minciencias y con código de registro COL0104976; 2) La Escuela Militar de Cadetes "General José María Córdova" y su Grupo de Investigación en Ciencias Militares categorizado en B por Minciencias y con código de registro COL0082556; y 3) La Escuela de Aviación del Ejército y su Grupo de Investigación en Aviación Militar categorizado en C por Minciencias y con código de registro COL0077618. Los puntos de vista y los resultados de este artículo pertenecen a los autores y no reflejan necesariamente los de las instituciones participantes.

DADOS, Rio de Janeiro, vol.64 (4): e20190193, 2021

https://doi.org/10.1590/dados.2021.64.4.247 
la academia, sus centros de pensamiento y grupos de investigación han buscado interpretar y transformar en conocimiento para toda la sociedad.

Esta visualización de la realidad colombiana por parte de los académicos abarca un amplio espectro de prácticas intelectuales que, en la mayoría de los casos, se registra en forma de publicaciones académicas. Estas últimas, a su vez, se desarrollan en pos de una gran variedad de objetos de estudio y registros investigativos, bajo la tutela de diversas teorías políticas y orientadas a distintos campos de acción y escenarios de intervención, mientras convocan, las más de las veces, reflexiones sobre la resolución de las diferencias y una reconciliación general.

Así las cosas, podría pensarse que la producción bibliográfica académica colombiana sobre el tema del conflicto armado y la paz explora meticulosamente todos los aspectos que puedan contribuir al entendimiento de los orígenes de esta problemática, a hacerle frente a los fenómenos aún existentes y a la prevención de nuevas violencias. Sin embargo, salvo los trabajos realizados por Bejarano (1985), Ortiz Sarmiento (1994), Nasi y Rettberg (2005), Zuleta (2006), Peñaranda (1987), Gutiérrez Loaiza (2012), Ramírez-Orozco (2014), Olave (2014) y Ruiz y Echeverry (2017), escasos esfuerzos se han realizado a la fecha para explorar y catalogar la extensa producción académica colombiana al respecto.

Existe, por tanto, un vacío general en cuanto a las particularidades de la producción de conocimiento sobre el conflicto armado y la paz en Colombia, en especial con un enfoque geopolítico, que ubique las temáticas investigadas y sus aportes, las tendencias de producción académica y sus geografías. La noción geopolítica de los espacios educativos se apoya en la idea de la naturaleza política de la educación y del pensamiento como una de sus posibilidades interpretativas, por lo cual "estas relecturas son necesarias para obligar al saber de las disciplinas a revisar los criterios que organizan su cultura académica y para diversificar el mapa de la producción intelectual" (Richard, 2002:5).

Dado este escenario, el presente artículo sostiene que la falta de categorización de la producción académica sobre el conflicto armado y la paz en Colombia ha contribuido a un desbalance en los aspectos investigados, así como al desconocimiento de elementos fundamentales para la compresión del contexto colombiano. A su vez, este vacío ha limitado el 
accionar de la academia, el Estado y sus instituciones, toda vez que no permite focalizar nuevos esfuerzos para el entendimiento del origen y la solución de la violencia, y el fortalecimiento de la paz y la democracia.

Ya que la producción académica espera aportar positivamente al proceso de comprensión del conflicto armado y la posibilidad de paz en el país, este artículo busca contribuir a este entendimiento mediante la identificación de las tendencias temáticas y objetos de investigación en la materia a nivel nacional. Asimismo, explora cómo y hacia dónde se han generado ejes de investigación respecto a este tema. En especial, se busca identificar las necesidades de futuras investigaciones sobre conflicto armado y paz en Colombia, con el fin de orientar los esfuerzos positivamente hacia la construcción del saber científico en las áreas requeridas, evitar la saturación y responder a necesidades reales de generación de nuevo conocimiento.

\section{LA GEOPOLÍTICA DEL CONOCIMIENTO: MÁS ALLÁ DE LA PRODUCCIÓN ACADÉMICA ENTRE NORTE Y SUR}

La idea de que existe algún tipo de geografía del conocimiento se considera cada vez más útil para comprender la producción y la circulación de saberes (Agnew, 2015). Lo mismo sucede con la conceptualización del proceso intuitivo que permite construir nociones teóricas compartidas a partir de la interrelación de ideas que están incorporadas en otros - familiares, maestros, colegas y vecinos (Shapin, 1998). A partir de estas premisas sociológicas - del sesgo geográfico de la creación y diseminación del conocimiento y de la vinculación de ideas del entorno -, es posible formular hipótesis sobre qué ideas surgen, dónde y cómo se adaptan a medida que circulan, y por qué algunas nunca llegan a convertirse en realidad.

Este proceso de generación de conocimiento se ha configurado entonces como una construcción permanente en la que se encuentran versiones sectorizadas sobre un fenómeno social y sus objetos de estudio. En efecto, en esta realidad, las ideologías de ciencia y sociedad tienden a universalizar la forma en que se aplica el conocimiento, a pesar de las diferencias reales de cada lugar, de sus condiciones de desarrollo y los contextos sociopolíticos (Jasanoff y Wynne, 1998; Lahsen, 2009). Téngase presente, además, que es también en este ejercicio de producción de las universidades, sus facultades y centros de investigación que se materializan relaciones de poder en sectores determinados. 
El conocimiento ha sido campo de lucha y de tensión porque dentro de él están en juego las diferentes representaciones y versiones de la verdad y de la realidad, los saberes que construyen estas verdades y la validez de cada una como también las intersecciones con asuntos de poder. (Walsh, 2007:65)

En el desarrollo de las ciencias, América Latina se convirtió en un lugar estudiado y no en un lugar donde se producen teorías y conocimiento propios, pues es tomado como objeto y no como sujeto de conocimiento. Pero el problema no radica solamente en la imposición del Norte, sino también en lo que se produce dentro y desde el mismo Sur (Walsh, 2007). Es así como el concepto de geopolítica del conocimiento forma un eje crucial en la comprensión crítica de la diferencia del conocimiento colonial frente a la formación y transformación del sistema moderno en América Latina.

Igualmente, tiene que ver con una mirada que interpela las tendencias epistemológicas que han prosperado en el campo del conocer universitario y delata, por otro lado, las tendencias fronterizas excluidas, para avanzar en un análisis amplio que incluye su sistema de relaciones, así como percata sus orígenes, intereses, localizaciones específicas y correlaciones desde la consideración del eje saber-poder (Solano y Caraballo, 2015:301). En el contexto de la crisis de los fundamentos, se evidencia la necesidad de instalar en la universidades y centros de investigación un tipo de discurso expresado como conocimiento hegemónico y homogéneo, construido como verdad única desde su lógica científica, racional, objetiva y neutra (Solano y Caraballo, 2015).

Bajo esta noción de geopolítica se asienta la construcción de conocimiento sobre el conflicto armado y la paz en Colombia, que ha buscado avanzar en diferentes líneas de análisis desde las cuales se reconoce la violencia y las interpretaciones de sus causas y efectos, que han marcado profundamente el territorio nacional.

Décadas de violencia política y social han puesto a Colombia en un lugar tristemente privilegiado para estudiar el fenómeno del conflicto armado, la inseguridad y la criminalidad. Al mismo tiempo, los intentos reiterados de solucionar el conflicto armado por vía negociada han aportado insumos para los estudios de las condiciones que rodean las negociaciones y la construcción de paz (Rettberg, 2010:21). 
A pesar de que la producción académica sobre este fenómeno social se ha presentado de manera continua en la historia contemporánea nacional, ha estado de cierta forma desligada de las tensiones propuestas desde la geopolítica del conocimiento, al asumir, desde las ciencias sociales, que lo que se produce sobre un conflicto armado interno es conocimiento situado o local. Sin embargo, dentro de los debates y la justificación intelectual importa saber cuáles son los problemas que requieren atención en el contexto nacional (Mignolo, 2003) y en el periodo actual de posacuerdo.

Así pues, a diferencia de los estudios anteriores en los que se categoriza la producción por ejes temáticos desde enfoques historiográficos (por ejemplo, Gutiérrez Loaiza, 2012; Nasi y Rettberg, 2005; Olave, 2014; Ortiz Sarmiento, 1994; Ramírez-Orozco, 2014), este artículo se concentra en el análisis de la producción bibliográfica a partir de un enfoque geopolítico, partiendo de las localizaciones y territorios donde se generan publicaciones académicas.

\section{EL CONFLICTO ARMADO, LA PAZ Y SU PRODUCCIÓN ACADÉMICA EN COLOMBIA}

La violencia que ha sufrido el país por más de cinco décadas ha dejado profundas marcas en las dinámicas sociales de los colombianos (Guanumen, 2015). Aun cuando la caracterización del conflicto armado es una actividad académica inacabada y sometida a continuas presiones y revisiones (Trejos Rosero, 2013), este artículo se vale de la estructura de cuatro periodos propuesta por el Centro Nacional de Memoria Histórica (CNMH) (2013). De acuerdo con este documento, el primer periodo va desde el surgimiento de la violencia bipartidista hasta la aparición de la violencia subversiva (1958-1982)1; sigue el periodo de expansión de los grupos de autodefensas (denominados también "grupos paramilitares") y las guerrillas, con la propagación del narcotráfico (1982-1996); continúa el periodo de la denominada polarización de la confrontación (1996-2000)2; y finaliza con las negociaciones en medio del conflicto (2005-2012).

Ligada al primer periodo de violencia se encuentra la elaboración de informes de parte de las diferentes comisiones de estudio establecidas en los últimos 50 años. Estas comisiones, ya sea por mandato 
gubernamental o dentro del marco del fin del conflicto bipartidista, integraron diagnósticos expertos que indagaron sobre las causas del conflicto desde diversas disciplinas (Vera Lugo, 2015).

En 1958 se instauró la primera de ellas: la Comisión Nacional Investigadora de las Causas y Situaciones Presentes de la Violencia en el Territorio Nacional y en la década de los 1980, se constituyó la Comisión de Estudio sobre la Violencia (1987). De esta última deriva el informe Colombia: violencia y democracia (Sánchez, 1987) 3 que marca el inicio de la violentología colombiana con el propósito de examinar las características estructurales del conflicto armado y sus posibles soluciones (Pizarro Leongómez, 1987, 1988, 1992; Ramírez, 1990; Reyes Posada y Bejarano, 1988). Luego de dos décadas, en el marco de la Comisión Nacional de Reparación y Reconciliación y en cumplimiento del mandato de la Ley 975 de 2005, se establece el Grupo de Memoria Histórica, dentro del periodo de justicia transicional ${ }^{4}$ (Jaramillo Marín, 2014; Sierra Zamora y Bermúdez Tapia, 2020).

A diferencia de las anteriores, la Comisión Histórica del Conflicto y sus Víctimas ${ }^{5}$ surge del acuerdo entre el Gobierno nacional y las Fuerzas Armadas Revolucionarias de Colombia (FARC) en 2014, con la misión de producir un informe sobre los orígenes y las múltiples causas del conflicto, los principales factores y condiciones que han facilitado o contribuido a su persistencia, y los efectos e impactos más notorios que tuvo sobre la población (Oficina del Alto Comisionado para la Paz, 2015) (Figura 1). 
Figura 1

Línea de tiempo de los procesos de paz, firma de acuerdos y producción de

\section{informes sobre conflicto armado}

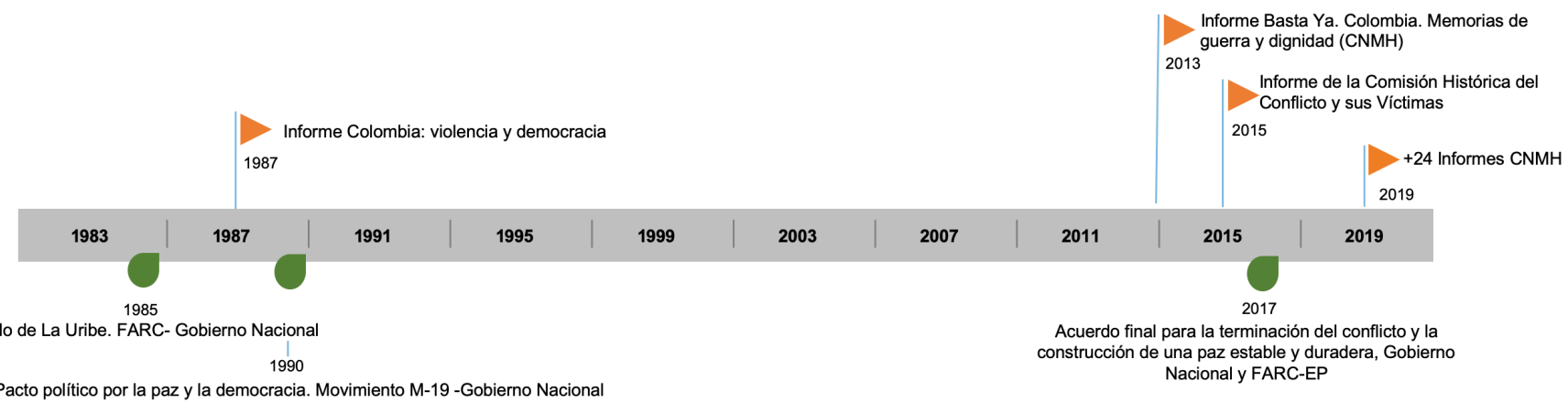

1983 - 1984 | Mesa de negociación entre las FARC-Gobierno Nacional

1984 - 1990 Mesa de negociación Movimiento M-19 -Gobierno Naciona

1984 - 1991

1987 - 1991 Desmovilización del grupo indigenista Quintín Lame y el PRT

1991 - 1992 Diálogos con La Coordinadora Guerrillera Simón Bolivar (FARC-EPL-ELN) y Gobierno Nacional

1993 - $1994 \quad$ Desmovilización de la CRS (disidencia del ELN)

Inicio de negociaciones entre el ELN y el EPL -Gobierno Nacional 1995 - 1998

Intento de diálogos de paz entre el ELN-Gobierno Nacional $\quad 1998-2002$

Zona de distensión de San Vicente del Caguán. FARC-Gobierno Nacional $\square$ 1999 - 2002

Intento de diálogos de paz entre el ELN -Gobierno Nacional 2002 - 2002

Intento de diálogos de paz entre el ELN -Gobierno Nacional I| 2003 - 2004

Acuerdo Santa fe de Ralito AUC -Gobierno Nacional $2003-2006$

Ocho (8) rondas exploratorias de negociación con el ELN 2005 - 2007

Proceso de negociación entre las FARC - Gobierno Nacional

Mesa de negociación entre el ELN y el Gobierno Nacional 2018 - 2019

Fuente: Elaboración propia con base en la información de López Gutiérrez (1999), Jaramillo Marín (2014), Niño González (2016), Villarraga Sarmiento (2015), Fundación Paz y Reconciliación (2016, 2019), Oficina del Alto Comisionado para la Paz (2015) y Centro Nacional de Memoria Histórica (2018). 
De forma paralela a esta producción, a inicios de la década del 1960, la investigación sobre la violencia presenta un enfoque partidista, que abarcaba desde obras de corte panfletario, periodístico y de crónica testimonial, hasta las que apuntaban al esclarecimiento en términos de responsabilidades de autores materiales e intelectuales (Oquist, 1978; Ortiz Sarmiento, 1992). No obstante, con la publicación del libro de Guzmán, Fals Borda y Umaña (1962) se crea una nueva estrategia para estudiar la violencia, en la que la búsqueda de estructuras, funciones, disfunciones, agrietamientos estructurales y vínculos sistémicos antes que el señalamiento de culpables o causas-autores - privilegió el papel del conflicto sobre la explicación de causa-efecto unilineal en la investigación (Valencia Gutiérrez, 2012).

Al dejar de justificarse en la acusación, la producción científico-social desarrollaría un enfoque propiamente historiográfico, lo cual estuvo respaldado por la fundación, hacia mediados de la década de los 1960, de programas académicos en ciencias sociales (Rueda, 2008), puesto que dichos programas introdujeron la violencia entre los objetos de narración y de análisis, especialmente en la sociología (Ortiz Sarmiento, 1994). La violencia, entonces, se constituyó en un objeto de la historia, la antropología y la ciencia política; esta última, encargada de ponerla como tema central en su producción investigativa y de introducir al Estado como actor ligado al fenómeno violento (Cartagena, 2016).

Ahora bien, la evolución de la lucha bipartidista en el país generó la recurrencia de múltiples delitos y violaciones a los derechos humanos (DD. HH.) y al derecho internacional humanitario (DIH), crímenes que se establecieron como rasgos estructurales de lo que se conoce como conflicto armado interno colombiano (Villamizar, 2018). Si bien el denominado paramilitarismo puede remontarse a la violencia de los años 1940 y 1950, cuando grupos armados de carácter privado operaron en complicidad con el Estado (Velásquez Rivera, 2007), su desarrollo puede situarse a mediados de los años 1960 cuando a través del decreto 3398 de 1965 y la Ley 48 de 1968 se dispuso que las Fuerzas Armadas organizaran la defensa nacional a través del entrenamiento y dotación de armamento militar a grupos de ciudadanos, para constituir grupos de autodefensa contrainsurgentes (Catatumbo, 1990; Medina Gallego, 1990; Reyes Posada, 1991). 
En la década de los 1980, el país se encontraba políticamente marcado por una intensificación del enfrentamiento armado y la irrupción de actores sociales en los escenarios de la violencia, así como por una inflexión en el tratamiento estatal del fenómeno guerrillero (Henderson, 1984; Palacios, 1999; Pecaut, 1991). Asimismo, a partir del surgimiento de grupos como las Autodefensas Campesinas de Córdoba y Urabá en 1994, y las Autodefensas Unidas de Colombia (AUC) en 1997, se imponen nuevas dinámicas dentro del conflicto - especialmente las económicas -, así como en la interdependencia entre los actores (Medina Gallego, 2005; Ronderos, 2014). En este momento, la violencia era una situación generalizada en el país.

Se puede estimar que la violencia puesta en marcha por estos grupos organizados constituyó el marco en el que se desarrolló todo tipo de violencia - política y no política (Pecaut, 1997). Esta nueva forma de violencia afectó regiones que no habían sido categorizadas como lugar de confrontación (Pecaut, 1999). Ante esta novedad, si bien llegaron a intentarse algunas propuestas que combinaban el diálogo directo y prolongado con los diversos grupos alzados en armas, la salida negociada entre las partes jamás llegó a consolidarse (Gutierrez López, 1999).

Estos nuevos actores y escenarios de negociación en la historia de la violencia fueron temas recurrentes entre las investigaciones de décadas posteriores (Álvarez Calderón y Rodríguez Beltrán, 2018; Sánchez, 2007). Mediante la valoración de la fuente oral, los antropólogos comprendieron de forma general - desde los estudios regionales y locales - la multiplicidad de causas de la violencia, su diferenciación regional y su relación con la problemática en sí del Estado (Blair Trujillo, 2009). Aun cuando la producción científico-social sobre la violencia ya podía reconocerse como tal por construir una mirada propia, las ciencias sociales seguían investigando la violencia pasada, sin explorar el campo de estudio de la violencia contemporánea (Rueda, 2008).

A finales de los años 1980, la producción bibliográfica sobre temas de violencia política aumenta, y con el transcurso del tiempo ya no se habla unívocamente de violencia, sino de muchas violencias entrecruzadas (Guerra y Plata, 2005), debido a la proliferación de grupos guerrilleros (Valencia Agudelo, 2013). Para los 1990, los estudios se caracterizan por proponer una visión panorámica de la violencia y los conflictos, y se concentran en hacer una marcada diferenciación 
entre ambos, además de reflexionar sobre los procesos de paz y los conflictos a nivel internacional, en una búsqueda de similitudes que indiquen posibles salidas para el caso colombiano (Ruiz Ocampo y Echeverry Martínez, 2017).

La intensificación de la violencia se manifestó en el incremento de acciones militares y la escalada de acciones de grupos armados, violaciones al DIH, sufrimiento para la población civil y crisis humanitaria (Barrero Velásquez, 2011; Martínez Lazcano, Pérez y Cubides Cárdenas, 2015; Soberón, 2002). Es en este contexto que surge la polarización de la confrontación entre actores ilegales, guerrilla y paramilitares, luego de que los gobiernos de este periodo introdujeran cambios en las políticas de paz que involucraban a la sociedad civil y a los mediadores internacionales, para favorecer las negociaciones, que culminarían sin éxito (Echandía Castilla, 2000). La instauración y el fracaso de la zona de distensión en el Caguán fue el evento que marcó este periodo (Pecaut, 2000).

Este fracaso fue dando lugar a una creciente tendencia en contra de la continuación de los procesos de negociación, ante los ataques terroristas de las FARC contra la infraestructura vial y energética, principalmente en los departamentos del Meta, Cundinamarca, Casanare, Antioquia, Tolima y Huila. Además, la ruptura de las negociaciones contribuyó a la expansión de la guerra hacia Nariño, Cauca, Valle, Norte del Huila y Tolima, y multiplicó los atentados terroristas en las grandes capitales del país (Solano y Caraballo, 2015).

Para este nuevo periodo, el creciente desarrollo de los estudios sobre las negociaciones de paz implicó un análisis renovado del conflicto y la violencia desde una marcada transformación epistemológica (Peñaranda, 1987). Destacan, además, los estudios sobre la legitimidad del orden y el ejercicio de la democracia. En una mirada desde los imaginarios, surgió toda una literatura dedicada a dar cuenta de los hechos acaecidos durante la violencia y la historia de las ideas, como una manera de realizar una catarsis y poder asimilar todo el horror que el conflicto significó en la vida de pueblos y veredas (Solano y Caraballo, 2015).

El último periodo inicia con las negociaciones en medio del conflicto armado, un periodo de solapamiento entre fases de posacuerdo, procesos de desarme, desmovilización y reintegración (DDR) e intentos de mesas de negociación (Melamed Visbal, 2014). Al inicio de este periodo 
se observa una desescalada del conflicto bastante fuerte, que llega a sus puntos más bajos en el 2010 (Calderón Rojas, 2016), situación que en 2012 dio el espacio para el inicio de los diálogos entre el Gobierno nacional y las FARC.

A inicios de la primera década de los años 2000, el centro de las inquietudes académicas del país correspondía a la intención de llegar a la paz: su construcción e implementación. En este sentido, abundan los estudios sobre los costos del conflicto armado y los aspectos económicos para construir la paz (Chavarro Miranda, Grautoff Laverde y Riaño Cruz, 2017; Valencia Agudelo, 2016; Vargas Pulido y Godoy Estrella, 2013) sobre los cuales ya se habían realizado algunos avances en la década de los 1990 (Deas y Gaitán, 1995; Granada y Rojas, 1995; Querubín, 2002; Sánchez y Díaz, 2005; Trujillo y Badel, 1998). Entre los temas de investigación resaltan las negociaciones con las FARC y las AUC, que ponen en evidencia la influencia de los eventos históricos más significativos en los esfuerzos y desaciertos que suponía la paz (Cubides Cárdenas y Garay Acevedo, 2013; Garay Acevedo y Guecha, 2018; Gutiérrez Loaiza, 2012; Pecaut, 2008).

Ya en los años siguientes, la producción académica sobre conflicto armado y paz aborda temas con miras a la construcción de la denominada paz territorial con una visión normativa complementaria. Ya no es solo la ausencia de la violencia o del conflicto armado lo que preocupa a los académicos del país (Aponte y Benavides, 2016; Mena Ortega, 2016), sino la inquietud por llenar el significado de la paz con mayor contenido, por imaginarlo, analizarlo y proyectarlo como realidad social, económica y política del país. "La visión académica en la actualidad se construye y fundamenta no solo en el análisis o la descripción de las experiencias que la realidad nos aporta, sino también en la formulación científica de las situaciones económicas, sociales y políticas, necesarias para hacer de la paz un proyecto realizable" (Ruiz Ocampo y Echeverry Martínez, 2017:45).

Es así como la simultaneidad entre el conflicto y el posconflicto ha sido un escenario recurrente durante la larga historia de intentos de paz en el país (Ramírez-Orozco, 2014). La investigación de este tema, por un lado, "ha estado estrechamente aliada a propósitos normativos y ha ofrecido insumos permanentes para la formulación de políticas públicas frente a situaciones de conflicto armado en plena actividad" (Nasi y Rettberg, 2005:73-74) y, por otro lado, con una mayor producción, ha 
estado dirigida a "dar cuenta del surgimiento de los grupos alzados en armas, al reconocimiento de sus causas, y posteriormente al análisis de los motivos que hicieron progresar, fallar o finalizar con éxito los distintos procesos de paz con dichos grupos" (Ruiz Ocampo y Echeverry Martínez, 2017:43). En especial, una de las preocupaciones que más ha estimulado la producción académica entre 2018 y 2019, aparte del DDR, la implementación y la justicia transicional, es la mirada territorial de las dinámicas del conflicto, los efectos de la violencia y la construcción de la paz. Al respecto se destacan los trabajos de Bechara Gómez (2012), Cairo et al. (2018), Estupiñán Achury (2018), Lederach (2017), Ríos Sierra y Gago Antón (2018) y Sierra Zamora (2020).

\section{IDENTIFICACIÓN Y CUANTIFICACIÓN DE LA PRODUCCIÓN ACADÉMICA SOBRE CONFLICTO ARMADO Y PAZ}

Las instituciones de educación superior colombianas, sus grupos y centros de investigación, se encuentran permanentemente sometidos a esquemas de medición por parte del Ministerio de Ciencia, Tecnología e Innovación (Minciencias) - denominado hasta el año 2019, Departamento Administrativo de Ciencia, Tecnología e Innovación (Colciencias) -, a través de su plataforma ScienTi y los aplicativos GrupLAC y CvLAC ${ }^{6}$. Este proceso de evaluación busca que "el conocimiento generado a partir de la investigación y del desarrollo tecnológico nacional, tenga un mayor impacto sobre el sistema productivo y contribuya a la solución de las problemáticas de la sociedad colombiana" (Colciencias, 2018:7). Asimismo, asigna categorías de calidad a la producción académica de la totalidad de los investigadores y grupos de investigación en Colombia ${ }^{7}$ allí registrados.

Los datos utilizados en este estudio fueron recopilados de la Plataforma ScienTI de Colciencias y de su aplicativo GrupLAC, con fecha de corte a 30 de mayo de 2019. Esto permitió lograr un alto nivel de actualización en la información de los grupos de investigación, toda vez que se realizó el análisis cuatro meses después del cierre de la ventana de observación establecida (31 de diciembre de 2018) por la Convocatoria Nacional nº 833 de Colciencias.

En una primera fase, se analizaron de forma individual los 5.202 grupos de investigación registrados en el servicio de consultas de la Plataforma ScienTI, para determinar cuáles dedicaban sus esfuerzos al análisis del conflicto armado y la paz en Colombia, con base en 
tres criterios: 1) el nombre del grupo; 2) su objetivo; y 3) las líneas de investigación. Este trabajo se realizó de manera independiente por parte de tres grupos de trabajo, cada uno conformado por un investigador principal y dos auxiliares de investigación, con el fin de reducir las posibilidades de error inter-observador o errores en el tratamiento de la información.

Los resultados individuales de los tres grupos de trabajo se cotejaron, en orden a buscar diferencias en la interpretación y parámetros de caracterización, labor que fue realizada por parte de un investigador y dos auxiliares externos al proyecto. Finalmente, los resultados de los tres grupos de trabajo se compararon para establecer una categorización definitiva de los 5.202 grupos de investigación. Como resultado, se obtuvieron 122 grupos (2,3\% del universo de análisis) que cumplían al menos dos de los criterios de selección (Tabla 1).

Tabla 1

Grupos de investigación de Colciencias

\begin{tabular}{lcc}
\hline Categoría grupos & $\begin{array}{c}\text { Total grupos Colciencias } \\
\%(\mathrm{n})\end{array}$ & $\begin{array}{c}\text { Grupos conflicto armado y paz } \\
\%(\mathrm{n})\end{array}$ \\
\hline A1 & $10,1 \%(523)$ & $2,3 \%(12)$ \\
\hline A & $14,6 \%(762)$ & $2,8 \%(21)$ \\
\hline B & $22,5 \%(1.169)$ & $2,7 \%(31)$ \\
\hline C & $40,6 \%(2.111)$ & $2,2 \%(46)$ \\
\hline Reconocido & $12,2 \%(637)$ & $1,9 \%(12)$ \\
\hline Total grupos & $100 \%(5.202)$ & $2,3 \%(122)$ \\
\hline
\end{tabular}

Fuente: Elaboración propia con base en la información de Colciencias (2019)

En una segunda fase, siguiendo un procedimiento igual al utilizado para el análisis de los grupos de investigación, se examinaron los productos bibliográficos resultantes de la generación de nuevo conocimiento $^{8}$ de los 122 grupos seleccionados. Los resultados se codificaron en tres categorías: 1) artículos de investigación en revistas indexadas tipo A1, A, B y C; 2) libros resultado de investigación; y 3) capítulos en libro resultado de investigación.

Se buscó identificar los productos que abordaron temáticas sobre el conflicto armado colombiano y la construcción de paz, con base en su título, palabras clave, resumen y contenido. Se eliminaron los pro- 
ductos registrados varias veces dentro del mismo grupo (por error en el ingreso de la información o por la autoría del producto por parte de varios investigadores pertenecientes al mismo grupo de investigación), así como los productos que no contaban con la información bibliográfica completa (título, autores, año de publicación, revista o editorial, ISSN o ISBN). Como resultado se determinó un nuevo universo de estudio de 1.092 publicaciones, correspondiente al 10,8\% de la producción de los grupos seleccionados (Tabla 2).

Estos productos pueden considerarse útiles para el presente estudio, ya que son la materialización de las investigaciones realizadas por personas, universidades o instituciones académicas, es decir, los documentos académicos son fundamentales en las diferentes etapas de la actividad investigativa y, además, evidencian el progreso científico y su impacto en el entorno (Corcione Nieto, Cabrera Cabrera y Latorre Rojas, 2020; García Jurado, 2018). Dentro del estudio se aplican indicadores bibliométricos para determinar la productividad de grupos y autores, su variación cronológica, sus investigaciones publicadas sobre el conflicto armado y paz en Colombia, así como sus aportes, debates y tendencias.

Tabla 2

Producción académica sobre conflicto armado y paz

\begin{tabular}{lcc}
\hline Producto & $\begin{array}{c}\text { Total producción grupos } \\
\text { conflicto armado y paz } \\
\%(\mathrm{n})\end{array}$ & $\begin{array}{c}\text { Producción sobre temas } \\
\text { conflicto armado y paz } \\
\%(\mathrm{n})\end{array}$ \\
\hline Artículos & $49,9 \%(5.193)$ & $9,9 \%(513)$ \\
\hline Libros & $14,8 \%(1.540)$ & $9,6 \%(148)$ \\
\hline Caṕ́tulos & $35,2 \%(3.365)$ & $12,8 \%(431)$ \\
\hline Total productos & $100 \%(10.098)$ & $10,8 \%(1.092)$ \\
\hline
\end{tabular}

Fuente: Elaboración propia con base en la información de Colciencias (2019).

En una última fase de sistematización, debido a la falta de consenso en las palabras clave utilizadas por los diversos tipos de publicaciones, se optó por usar las disposiciones en acuerdos de paz a nivel mundial (Instituto Kroc de Estudios Internacionales para la Paz, 2019), que se agrupan en cinco grandes conjuntos: 1) disposiciones socioeconómicas; 2) políticas; 3) seguridad y defensa; 4) justicia; y 5) verificación e implementación. Estos grupos, a su vez, presentan un total de 51 subcategorías, las cuales se convirtieron 
en las palabras clave para cada uno de los productos registrados. Con esta información contenida en una base de datos se realizó el análisis descriptivo para generar los resultados que se presentan a continuación.

\section{TRANSFORMACIONES EN LAS GEOGRAFÍAS DE LA PRODUCCIÓN CIENTÍFICA SOBRE CONFLICTO ARMADO Y PAZ}

Para valorar la actividad científica sobre el conflicto, la violencia y la paz, se procedió a un análisis descriptivo de las investigaciones desarrolladas en los diferentes contextos académicos, metodología mediante la cual es posible agrupar los trabajos y reconocer de esta manera el avance que se ha dado en investigación en un país.

Antes de 1994, la producción académica de los grupos de investigación colombianos sobre conflicto armado y paz registrada en la plataforma GrupLAC es escasa. En los años siguientes, esta producción se incrementó de forma errática, con una tendencia lineal (Figura 2). El producto con menor tasa de crecimiento son los libros, en tanto que los artículos y los capítulos de libro tuvieron un incremento similar. En el periodo comprendido entre 1997 y 2010 se produjeron más artículos que capítulos de libro (Figura 2).

Figura 2

Producción académica colombiana sobre conflicto armado y paz por año

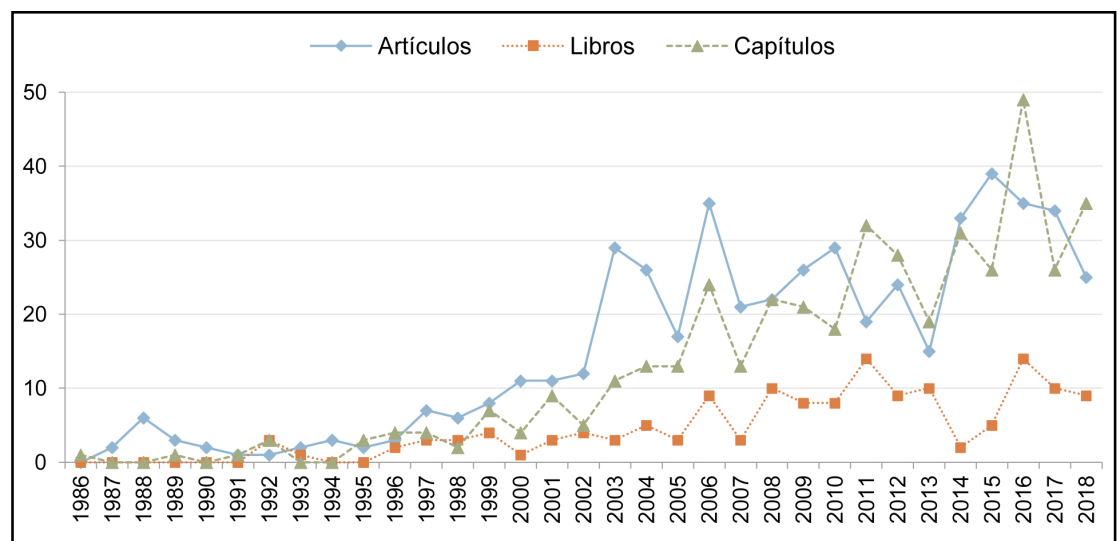

Fuente: Elaboración propia con base en la información de Colciencias (2019). 
La productividad de los grupos de investigación referida al conflicto armado y la paz se encuentra en alrededor del $10 \%$, con un rango de variación bajo, entre 9,8\% y 12,8\%. Este último valor corresponde a los capítulos de libro, y responde al incremento en la tasa de productividad representada en la Figura 2.

En el marco del universo evaluado, los grupos de investigación que se categorizan como reconocidos por Colciencias son los de menor productividad; sin embargo, generan un mayor porcentaje de productos relacionados con el conflicto armado y la paz, particularmente artículos y libros, frente a los grupos mejor categorizados (Tabla 3). En contraste, los grupos en la categoría $C$ tienen el porcentaje de publicaciones sobre conflicto armado y paz más bajo, lo que también es evidente en artículos científicos y libros (Tabla 3).

Tabla 3

Producción académica sobre conflicto armado y paz por categoría

\begin{tabular}{lcccccccccc}
\hline \multirow{2}{*}{$\begin{array}{l}\text { Categoría } \\
\text { grupos }\end{array}$} & \multicolumn{3}{c}{ Total productos } & \multicolumn{3}{c}{$\begin{array}{c}\text { Productos conflicto } \\
\text { armado y paz }\end{array}$} & \multicolumn{3}{c}{$\begin{array}{c}\text { Productividad conflicto } \\
\text { armado y paz }\end{array}$} \\
\cline { 2 - 12 } & $\begin{array}{c}\text { Artícu- } \\
\text { los }\end{array}$ & Libros & $\begin{array}{c}\text { Capí- } \\
\text { tulos }\end{array}$ & $\begin{array}{c}\text { Artícu- } \\
\text { los }\end{array}$ & Libros & $\begin{array}{c}\text { Capí- } \\
\text { tulos }\end{array}$ & $\begin{array}{c}\text { Artícu- } \\
\text { los }\end{array}$ & Libros & $\begin{array}{c}\text { Capí- } \\
\text { tulos }\end{array}$ & Total \\
\hline A1 & 1.354 & 324 & 870 & 142 & 31 & 125 & $10,5 \%$ & $9,6 \%$ & $14,4 \%$ & $11,5 \%$ \\
\hline A1 & 1.442 & 401 & 1.128 & 162 & 40 & 121 & $11,2 \%$ & $10,0 \%$ & $10,7 \%$ & $10,6 \%$ \\
\hline B & 1.147 & 379 & 848 & 121 & 47 & 94 & $10,5 \%$ & $12,4 \%$ & $11,1 \%$ & $11,3 \%$ \\
\hline C & 897 & 296 & 547 & 43 & 10 & 56 & $4,8 \%$ & $3,4 \%$ & $10,2 \%$ & $6,1 \%$ \\
\hline Reconocido & 353 & 140 & 272 & 45 & 20 & 35 & $12,7 \%$ & $14,3 \%$ & $12,9 \%$ & $13,3 \%$ \\
\hline Total & 5.193 & 1.540 & 3.665 & 513 & 148 & 431 & $9,9 \%$ & $9,6 \%$ & $12,8 \%$ & $10,8 \%$ \\
\hline
\end{tabular}

Fuente: Elaboración propia con base en la información de Colciencias (2019).

Los grupos de investigación pertenecientes a instituciones de carácter público publicaron menos productos que los pertenecientes a instituciones de carácter privado. De igual modo, el porcentaje que destinaron a temas relativos al conflicto armado y la paz también es menor, en efecto, a producción de libros y capítulos fue menos de la mitad en grupos de investigación de instituciones públicas (Tabla 4). 
Tabla 4

Producción académica sobre conflicto armado y paz por tipo

\begin{tabular}{|c|c|c|c|c|c|c|c|c|c|c|}
\hline \multirow{2}{*}{ Tipo grupos } & \multicolumn{3}{|c|}{ Total productos } & \multicolumn{3}{|c|}{$\begin{array}{c}\text { Productos conflicto } \\
\text { armado y paz }\end{array}$} & \multicolumn{4}{|c|}{$\begin{array}{c}\text { Productividad conflicto armado } \\
\text { y paz }\end{array}$} \\
\hline & $\begin{array}{l}\text { Artícu- } \\
\text { los }\end{array}$ & Libros & $\begin{array}{l}\text { Capí- } \\
\text { tulos }\end{array}$ & $\begin{array}{l}\text { Artícu- } \\
\text { los }\end{array}$ & Libros & $\begin{array}{l}\text { Capí- } \\
\text { tulos }\end{array}$ & $\begin{array}{l}\text { Artícu- } \\
\text { los }\end{array}$ & Libros & $\begin{array}{l}\text { Capí- } \\
\text { tulos }\end{array}$ & Total \\
\hline Público & 2.130 & 577 & 1.147 & 212 & 45 & 130 & $10,0 \%$ & $7,8 \%$ & $11,3 \%$ & $9,7 \%$ \\
\hline Privado & 3.063 & 963 & 2.518 & 301 & 103 & 301 & $9,8 \%$ & $10,7 \%$ & $12,0 \%$ & $10,8 \%$ \\
\hline Total & 5.193 & 1.540 & 3.665 & 513 & 148 & 431 & $9,9 \%$ & $9,6 \%$ & $12,8 \%$ & $10,8 \%$ \\
\hline
\end{tabular}

Fuente: Elaboración propia con base en la información de Colciencias (2019).

La región colombiana en donde se registra la mayor producción total por parte de los grupos de investigación es la región Andina, seguida por la Pacífica, Caribe y Amazonía (Tabla 5). Esta tendencia obedece a la publicación de un mayor número de artículos y libros. Por el contrario, el número de capítulos de libro referidos al conflicto armado y la paz es mayor en la región Caribe que en la Pacífica. Para el caso de la Orinoquía no se encontraron investigaciones hechas por los grupos registrados y solamente se produjo un capítulo de libro en la Amazonía (Tabla 5).

Tabla 5

Producción académica sobre conflicto armado y paz por región

\begin{tabular}{lccccccccccc}
\hline \multirow{2}{*}{$\begin{array}{l}\text { Categoría } \\
\text { grupos }\end{array}$} & \multicolumn{3}{c}{ Total productos } & \multicolumn{3}{c}{$\begin{array}{c}\text { Productos conflicto } \\
\text { armado y paz }\end{array}$} & \multicolumn{3}{c}{$\begin{array}{c}\text { Productividad conflicto } \\
\text { armado y paz }\end{array}$} \\
\cline { 2 - 11 } & $\begin{array}{c}\text { Artícu- } \\
\text { los }\end{array}$ & Libros & $\begin{array}{c}\text { Capí- } \\
\text { tulos }\end{array}$ & $\begin{array}{c}\text { Artícu- } \\
\text { los }\end{array}$ & Libros & $\begin{array}{c}\text { Capí- } \\
\text { tulos }\end{array}$ & $\begin{array}{c}\text { Artícu- } \\
\text { los }\end{array}$ & Libros & $\begin{array}{c}\text { Capí- } \\
\text { tulos }\end{array}$ & Total \\
\hline Andina & 4.270 & 1.323 & 3.058 & 455 & 143 & 395 & $10,7 \%$ & $10,8 \%$ & $12,9 \%$ & $11,5 \%$ \\
\hline Caribe & 277 & 83 & 302 & 23 & 2 & 23 & $8,3 \%$ & $2,4 \%$ & $7,6 \%$ & $6,1 \%$ \\
\hline Pacífico & 624 & 120 & 279 & 35 & 3 & 12 & $5,6 \%$ & $2,5 \%$ & $4,3 \%$ & $4,1 \%$ \\
\hline Amazonía & 22 & 14 & 26 & - & - & 1 & $0,0 \%$ & $0,0 \%$ & $3,8 \%$ & $1,3 \%$ \\
\hline Orinoquía & - & - & - & - & - & - & $0,0 \%$ & $0,0 \%$ & $0,0 \%$ & $0,0 \%$ \\
\hline Total & 5.193 & 1.540 & 3.665 & 513 & 148 & 431 & $9,9 \%$ & $9,6 \%$ & $12,8 \%$ & $10,8 \%$ \\
\hline
\end{tabular}

Fuente: Elaboración propia con base en la información de Colciencias (2019).

Como es de esperarse, el área de conocimiento de los grupos de investigación que presenta la mayor cantidad de producción es la de las ciencias sociales, seguida por las ciencias agrícolas, las ciencias de la salud y las 
humanidades (Tabla 6). Por su parte, las ciencias agrícolas presentan un porcentaje de publicación de libros notoriamente más bajo, en relación con los artículos científicos y los capítulos de libro de esta área.

Tabla 6

Producción académica sobre conflicto armado y paz por gran área de conocimiento

\begin{tabular}{|c|c|c|c|c|c|c|c|c|c|c|}
\hline \multirow{2}{*}{$\begin{array}{l}\text { Área cono- } \\
\text { cimiento }\end{array}$} & \multicolumn{3}{|c|}{ Total productos } & \multicolumn{3}{|c|}{$\begin{array}{c}\text { Productos conflicto } \\
\text { armado y paz }\end{array}$} & \multicolumn{4}{|c|}{$\begin{array}{c}\text { Productividad conflicto } \\
\text { armado y paz }\end{array}$} \\
\hline & $\begin{array}{l}\text { Artícu- } \\
\text { los }\end{array}$ & Libros & $\begin{array}{l}\text { Capí- } \\
\text { tulos }\end{array}$ & $\begin{array}{l}\text { Artícu- } \\
\text { los }\end{array}$ & Libros & $\begin{array}{l}\text { Capí- } \\
\text { tulos }\end{array}$ & $\begin{array}{l}\text { Artícu- } \\
\text { los }\end{array}$ & Libros & $\begin{array}{l}\text { Capí- } \\
\text { tulos }\end{array}$ & Total \\
\hline C. sociales & 4.265 & 1.326 & 3.199 & 454 & 141 & 397 & $10,6 \%$ & $10,6 \%$ & $12,4 \%$ & $11,2 \%$ \\
\hline C. salud & 443 & 45 & 105 & 26 & 3 & 6 & $5,9 \%$ & $6,7 \%$ & $5,7 \%$ & $6,1 \%$ \\
\hline C. agrícolas & 310 & 119 & 274 & 32 & 4 & 28 & $10,3 \%$ & $3,4 \%$ & $10,2 \%$ & $8,0 \%$ \\
\hline $\begin{array}{l}\text { Humani- } \\
\text { dades }\end{array}$ & 175 & 50 & 87 & 1 & - & - & $0,6 \%$ & $0,0 \%$ & $0,0 \%$ & $0,2 \%$ \\
\hline Total & 5.193 & 1.540 & 3.665 & 513 & 148 & 431 & $9,9 \%$ & $9,6 \%$ & $12,8 \%$ & $10,8 \%$ \\
\hline
\end{tabular}

Fuente: Elaboración propia con base en la información de Colciencias (2019).

Se identificaron 38 categorías de las disposiciones de procesos de paz (Tabla 7) en la producción académica sobre conflicto armado y paz. La categoría de mayor interés ha sido la de los mecanismos de verdad o reconciliación, con una alta producción de artículos, seguida de capítulos de libro. El segundo lugar de producción lo tiene la disposición de personas desplazadas. Cabe resaltar que son varios los casos en los que los subtemas solamente tienen uno o dos productos. Por ejemplo, los derechos de las minorías y los derechos de las minorías indígenas tienen dos productos cada una. En último lugar, con un solo producto, se encuentran disposiciones tan variadas como amnistía, desarme y protecciones culturales (Tabla 7). 
Tabla 7

Producción académica sobre conflicto armado y paz por disposiciones de procesos de paz

\begin{tabular}{|c|c|c|c|c|c|c|c|}
\hline Disposición & Artículos & Libros & Capítulos & Disposición & Artículos & Libros & Capítulos \\
\hline Amnistía & - & - & 1 & Mecanismo verdad o reconciliación & 203 & 71 & 173 \\
\hline Arbitraje internacional & 2 & - & 3 & Personas desplazadas & 57 & 14 & 45 \\
\hline Cese al fuego & 3 & - & 1 & Poder territorial compartido & 2 & - & - \\
\hline Comisión para solucionar daños & - & 1 & - & Protecciones culturales & 1 & - & - \\
\hline Demarcación de fronteras & 8 & 1 & 6 & Reforma a la ciudadanía & 10 & 8 & 6 \\
\hline Derecho de autodeterminación & 1 & - & - & Reforma a la rama ejecutiva & 1 & - & - \\
\hline Derechos de las minorías & - & - & 2 & Reforma a la rama judicial & 10 & 1 & 15 \\
\hline Derechos de las minorías indígenas & 1 & - & 1 & Reforma a la rama legislativa & 2 & 1 & 4 \\
\hline Derechos de las mujeres & 8 & 7 & 11 & Reforma constitucional & 2 & 1 & 4 \\
\hline Derechos de los niños & 7 & 2 & 8 & Reforma de medios comunicación & 8 & 2 & 2 \\
\hline Derechos humanos & 26 & 4 & 16 & Reforma educativa & 7 & 4 & 7 \\
\hline Derechos minorías indígenas & - & - & 2 & Reforma electoral / partidos políticos & 7 & 3 & 9 \\
\hline Desarme & - & - & 1 & Reforma militar & 8 & 5 & 13 \\
\hline Desarrollo económico y social & 36 & 5 & 27 & Reforma policial & 2 & - & 2 \\
\hline Desmovilización & 1 & 2 & 4 & Refugiados & 3 & - & 2 \\
\hline Grupos paramilitares & 25 & 2 & 16 & Reinserción & 8 & 1 & 6 \\
\hline Manejo de recursos naturales & 4 & 1 & 2 & Relaciones interétnicas / Estado & - & - & 1 \\
\hline Mecanismo de ratificación & 5 & 1 & 3 & Reparaciones & 21 & 3 & 17 \\
\hline Mecanismo de verif. / monitoreo & 5 & - & 5 & Revisión del acuerdo & 24 & 6 & 10 \\
\hline
\end{tabular}

Fuente: Elaboración propia con base en la información de Colciencias (2019). 
Los capítulos de libro han tratado 33 disposiciones de las 38 identificadas, promedio muy cercano la cantidad de disposiciones tratadas en los artículos (32 disposiciones de 38); mientras que los libros han tratado 23 disposiciones, entre las cuales resaltan personas desplazadas, derechos de las mujeres y revisión de los acuerdos (Tabla 7).

La Figura 3 evidencia que, de forma tradicional, la producción de artículos científicos sobre conflicto armado y paz ha sido mayor que la de los otros dos tipos de producto evaluados. No obstante, se exhiben algunas particularidades. El subtema "justicia" ha sido tratado de forma persistente desde el primer año de medición de este estudio. Posteriormente, en 1988, comenzaron a aparecer subtemas como "seguridad y defensa" y "verificación e implementación", que no registran producción en 2006, pero que son constantes desde 2011 hasta el año de corte de este análisis; en este último subtema se encuentran las categorías "víctimas", "reparación" y "verdad". Solo hasta 1996 apareció en el escenario el subtema referido como "socioeconómicas"; mientras que, el subtema "políticas" desaparece entre 1989 y 1997, para nuevamente reaparecer en 2001. 
Figura 3

Agrupación de la producción académica colombiana sobre conflicto armado y paz por disposiciones

\#Artículos $\square$ Libros $\square$ Capítulos

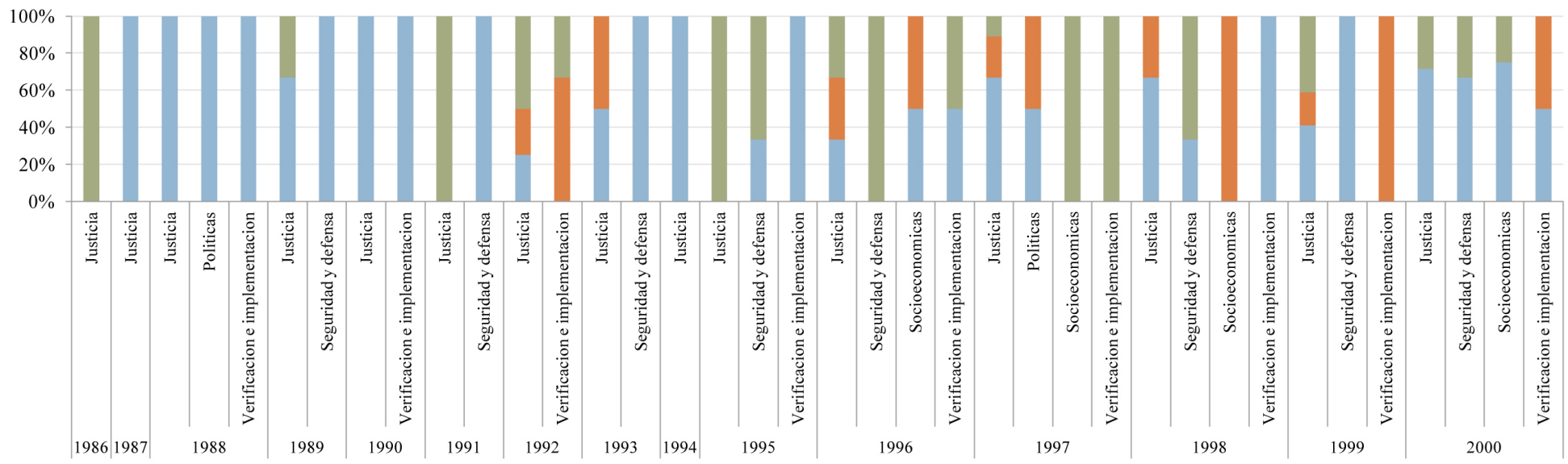


Figura 3

Agrupación de la producción académica colombiana sobre conflicto armado y paz por disposiciones (continuación)

artículos $\square$ Libros $\square$ Capítulos

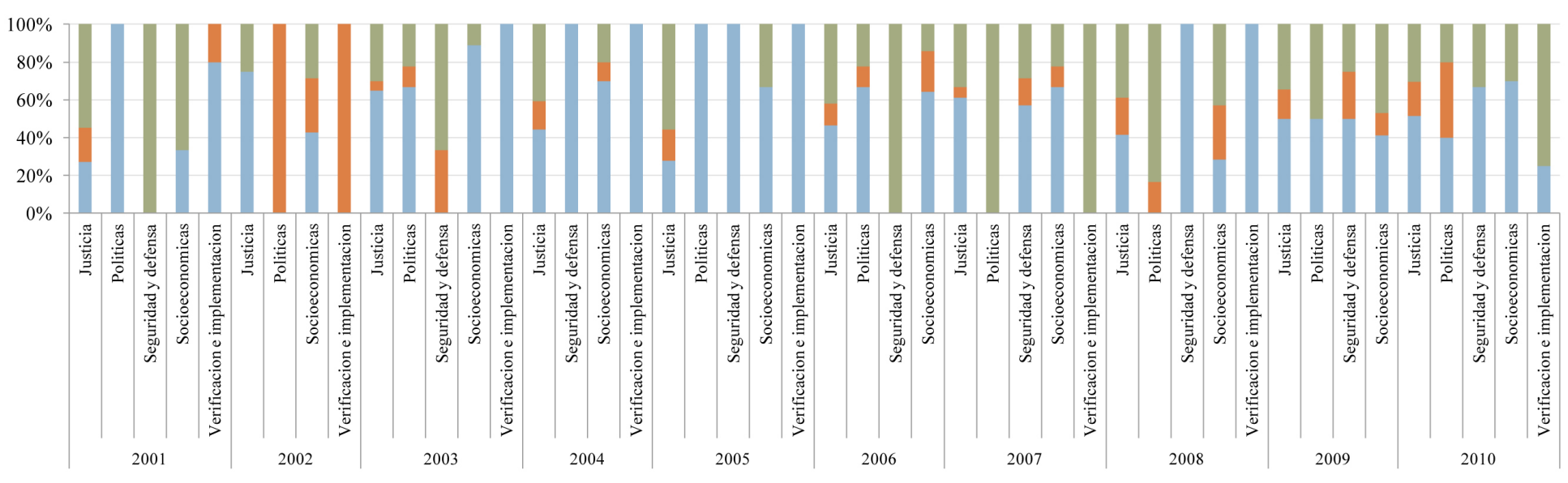


Figura 3

Agrupación de la producción académica colombiana sobre conflicto armado y paz por disposiciones (continuación)

$\square$ Artículos $\square$ Libros $\square$ Capítulos

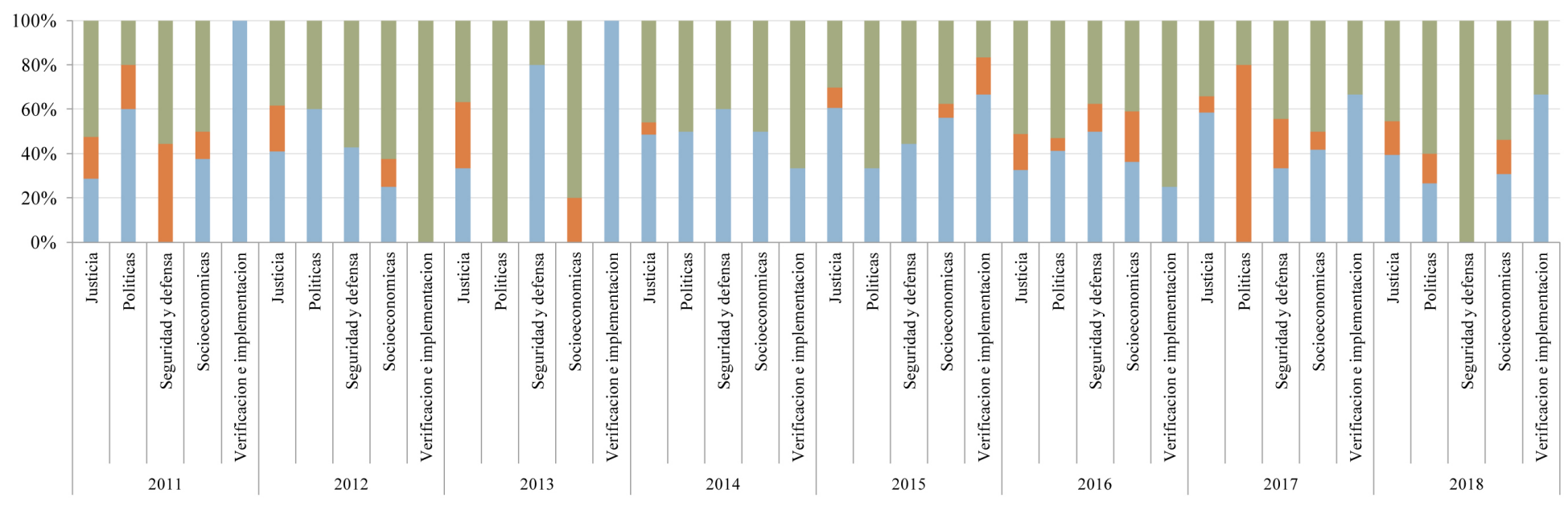

Fuente: Elaboración propia con base en la información de Colciencias (2019). 
Por otro lado, el incremento general del número de publicaciones (Figura 2) ha ido de la mano con la diversificación en el tipo de publicación (Figura 3). Es así como, desde el inicio del periodo de medición, se observa que en varias ocasiones el $100 \%$ de las publicaciones sobre un subtema determinado es generado a partir de un único tipo de producto, lo que en los últimos años dejó de suceder, dándole paso a los capítulos de libro como productos de gran producción. Para el caso de los libros, su publicación se mantiene baja a lo largo de las décadas (Figura 3).

\section{ESPACIALIDADES, EJES Y TEMPORALIDADES EN LA PRODUCCIÓN SOBRE CONFLICTO ARMADO Y PAZ EN COLOMBIA}

De acuerdo con Segato (2015:5), si el concepto de geopolítica cruza y combina geografía con teoría del poder, y predica región y localidad en términos de sus relaciones de control, necesariamente una geopolítica del conocimiento forma parte integral de la construcción y organización de lo que se puede llamar escenario global. De esta forma, la historia del conocimiento está marcada geohistórica, geopolítica y geoculturalmente: tiene valor, color y lugar de origen (Walsh, 2007). En efecto, como el conocimiento se encuentra naturalizado dentro de la sociedad por su origen científico, da lugar a entornos locales que tienen valor y sentido en relación con los contextos sociales y culturales en que son producidos (Echeverri, 2001). Este es el lugar en el que se inscribe el conocimiento y la producción sobre conflicto y paz en el país: no son solo los cambios internos del discurso dentro de los grupos de científicos sociales los que han repercutido en la historiografía de la violencia, sino los cambios exteriores de la vida política del país los que han atravesado y atraviesan la cotidianidad de los investigadores dedicados a su estudio (Ortiz Sarmiento, 1994).

Si bien los análisis sobre la violencia se han asociado tradicionalmente a los informes producidos por las comisiones de estudio establecidas y a las trayectorias y debates que adelantaron los investigadores y funcionarios que hicieron parte de ellas (Vera Lugo, 2015), las facultades de ciencias sociales y sus centros de investigación encontraron un lugar para la producción y difusión de estudios sobre los fenómenos sociales de la violencia, el conflicto y la paz (Cabrera Cabrera et al., 2018). 
Existieron en la década de los 1980, dentro de la producción científico-social de la violencia, dos eventos relevantes como punto de partida en el análisis de la producción sobre conflicto y paz: el Primer Simposio Internacional sobre la Violencia en 1984 y la Comisión de Estudios sobre la Violencia en 1987 (Ortiz Sarmiento, 1994). Ambos eventos se desarrollaron en un escenario en el que, por una parte, la institucionalización de carreras de ciencias sociales incidía en el contexto nacional (Valencia Agudelo, 2016) y, por otra, se identificaba por primera vez que la violencia tenía múltiples expresiones que no excluían pero sí sobrepasaban la dimensión política. Esta condición transformó los centros urbanos en ciudades cercadas donde la vida transcurrió de manera normal, cada vez más aisladas de los campos minados y trincheras militares que marcaron la vida cotidiana de los habitantes de las periferias (Serje, 2006). Es en esta década que se empieza a hablar de propuestas de finalización del conflicto por vía negociada y se desarrolla, en consecuencia, un nuevo escenario para la producción en materia de paz.

Con varios fracasos y pocos éxitos en el panorama de las negociaciones entre el gobierno y los diversos grupos guerrilleros, al entrar los años noventa se diversifican los estudios sobre el conflicto y la paz: las comunidades científicas nacionales convierten la violencia en objeto de estudio (Zuleta, 2006). Estas últimas se hallaban

[...] nutridas por un continuo proceso de profesionalización de las ciencias sociales, por la multiplicación de disciplinas interesadas en los fenómenos nacionales, por la descentralización institucional de los estudios y por desarrollos internacionales -en la política y en la academia - que marcaron los temas estudiados y las metodologías aplicadas (Rettberg, 2010:24).

Simultáneamente, la reorganización de Colciencias en esta década crea el denominado Sistema Nacional de Ciencia, Tecnología e Innovación (SNCTI), con el fin de integrar las actividades científicas, tecnológicas y de innovación (República de Colombia, 1991). Con la modalidad abierta del SNCTI, empieza el registro de la investigación científica y la producción académica de las organizaciones públicas, privadas o mixtas en la plataforma CvLAC (así como la vinculación de sus grupos). 
Es así como la producción de libros tiene un desarrollo constante a lo largo de los primeros años de registro, continuando con un incremento gradual en los 1990. Por su parte, el destacado aumento de la publicación de artículos en revistas indexadas se liga a la concepción de que las revistas especializadas de carácter científico son evidencia de la originalidad y pertinencia de los objetos de estudio, además de entenderse como un reflejo del funcionamiento de las ciencias en general y sus investigadores (Colciencias, 2016). A su vez, este aumento coincide con la dinámica propia de las revistas en el mundo, y particularmente en Colombia, en donde para el año 2000 se establece Publindex, como una iniciativa estatal de normalización, evaluación y clasificación de publicaciones periódicas científicas (Flórez Carranza, 2018).

A partir de entonces, la publicación de libros, capítulos de libro y artículos presenta una aproximación integral de la violencia y del conflicto, entendidos como fenómenos contemporáneos recurrentes, superpuestos $\mathrm{y}$, para este periodo, complementarios. Al lado de este fenómeno se inscriben también los procesos de paz (Valencia Agudelo, 2017), concebidos no solo como un momento puntual y unidimensional, sino como un conjunto de fases o etapas distribuidas en el tiempo, en las que intervienen todos los actores afectados, en un esfuerzo colectivo por alcanzar, en un momento determinado, acuerdos que permitan acabar con la situación anterior, dominada por la violencia y el enfrentamiento armado (Sánchez, 2014). Cabe resaltar que el ligero aumento de publicación de artículos que se observa para 1997 concuerda con el periodo de inicio de las negociaciones con las FARC y el establecimiento, al año siguiente, de la zona de distensión del Caguán, lo que constituyó un escenario propicio para la investigación de temas como la "verificación e implementación".

De acuerdo con este recorrido, al comenzar un nuevo siglo se tienen unas ciencias sociales y humanas modernas, con una renovación en sus teorías, técnicas de investigación, metodologías y objetos de estudio (Valencia Agudelo, 2016). Aunque mejoraron sus condiciones para el ejercicio profesional, la polarización política influyó, sobre todo, en la ciencia política, cuya capacidad analítica se vio mermada (Leal Buitrago, 2013). No obstante, es en esta década que se inicia el estudio de nuevos temas asociados al conflicto armado, como el narcotráfico (Betancourt Echeverry, 1991; Niño González, 2016; Palacio y Rojas, 
1990; Palma Morales, 2012) o el terrorismo. Este último, en particular después de los atentados del 11 de septiembre de 2001 (Nasi y Rettberg, 2005), se presenta como un tema recurrente de análisis.

En el 2006, un año después de la implementación de la Ley 975 de 2005, conocida como Ley de Justicia y Paz, la cantidad de documentos consignados en la plataforma GrupLAC se incrementó con respecto al año anterior, con la producción más alta entre los artículos registrados en la primera parte del milenio. Sin embargo, contrario a lo que se presentó en 1997, en el 2006 no se registra producción en la categoría de "verificación e implementación", pero sí emergen diversos recursos metodológicos, en especial la memoria - que hace confluir disciplinas como la historia, la antropología, la sociología y la ciencia política- y que centra la investigación en un tema del conflicto hasta entonces olvidado: las víctimas.

Para el 2012, la generación de artículos se convirtió en uno de los temas fundamentales de medición en las instituciones de educación superior (IES). En efecto, durante este periodo Colombia se posicionó como el quinto país de la región con mayor número de artículos académicos, con 5.000 registros (Semana, 2018), manteniéndose esa tendencia aun a pesar del incremento en las exigencias de calidad por parte del Departamento Administrativo de Ciencia, Tecnología e Innovación, Colciencias, (Corchuelo-Rodríguez, Patacón-Ruiz y Piza-Amado, 2020; Fernandez-Osorio, 2019a). Con estos resultados, los cuestionamientos acerca de la excelencia en las publicaciones por parte de Colciencias y su contrario, las críticas de los grupos de investigación en ciencias sociales y humanas hacia esta entidad y hacia las políticas públicas sobre desarrollo e investigación científica (Franco Mongua, Villalba Cuéllar y González Serrano, 2015) se hicieron cada vez mayores, sin que afectaran el registro de producción para el 2015 y los años siguientes.

El informe de la Comisión Histórica del Conflicto y sus Víctimas (2015) evidenció la larga producción investigativa que sobre este tema se había generado; asimismo, expuso cómo desde las ciencias sociales se siguen produciendo nuevas explicaciones sobre el origen, la dinámica y la situación actual de la violencia en el país (Bermúdez Quintana et al., 2018; Sierra Zamora, Bermúdez Tapia y Pedraza Mariño, 2020c; Jaramillo Marín, 2014), apreciación que se plasma en el registro de artículos para el año de publicación de este informe. 
En relación con los capítulos de libro, si bien su producción describe un patrón de incremento lineal, en el 2016 se presenta un aumento en el registro. Este año coincide con la firma de los acuerdos entre el Gobierno nacional y las FARC-EP. Los diálogos de paz en La Habana configuraron un hito importante en la historia del conflicto armado en el país, especialmente en cuanto al alcance de una paz estable y duradera (Cubides Cárdenas y Sierra Zamora, 2020; Fernandez-Osorio, 2019b; Higuita, 2014; Quintero Cordero, 2020; Torrijos Rivera y Abella Osorio, 2018) desde un enfoque territorial (Sierra Zamora, Bermúdez Tapia y Arango Calderón, 2020b; Rios Sierra, 2017), lo que motivó múltiples preguntas y reflexiones que se materializaron y siguen materializándose en producciones científicas para este último periodo.

A lo largo de los diferentes ciclos de intentos, negociaciones y procesos de paz, periodos de posacuerdo y un conflicto armado constante y transformado, se pone en evidencia la relación que ha existido entre el desarrollo y la consolidación de las ciencias sociales en Colombia y el estudio de la violencia (Cubides Cárdenas et al., 2019; Valencia Agudelo, 2016). Esta relación entregó a los estudiosos de las ciencias sociales inscritos en ámbitos académicos un objeto de estudio primordial: la violencia fue y sigue siendo un campo prolífico de investigación.

Ahora bien, a través de esta relación geohistórica entre la violencia y el desarrollo de las ciencias sociales, se puede ahondar en la geografía del conocimiento. Desde la propia hetereogeneidad de la sociedad colombiana, la manera desigual y diferenciada en la que el Estado se hace presente se expresa en la combinación de un país selectivamente modernizado, con regiones donde esta presencia es más indirecta, y otras zonas donde no existe una presencia eficaz de las instituciones estatales. Aunado a lo anterior, existe una diferenciación espacial y temporal de las violencias, que no giran en torno a una polarización, sino que sus contradicciones se producen en torno a dinámicas de distinto orden y a procesos históricos de cambios en el control de los diferentes territorios (Bermúdez Tapia, Sierra Zamora y Fernandez Osorio, 2020b; González, 2002).

Como caso particular y opuesto a lo que se observa en la región Andina, se presenta una desvinculación entre la violencia sucedida en la Orinoquía colombiana y la producción científica (capítulos de libro, artículos y libros) en torno a temas relacionados con el conflicto armado y la paz. La relación entre el número de investigadores por unidad de 
área en esta región está entre las más bajas del país. Este factor, sumado a que el interés de los grupos de investigación en temas de conflicto armado y paz no supera el 15\% en todo el territorio nacional, puede explicar la inexistencia de publicaciones producidas en esta región. No obstante, es importante considerar que, si bien desde la región misma no se muestra producción sobre estos temas debido a la dinámica de lo que Uribe (2001) llama "fragilidad de la soberanía estatal" - en la que la soberanía interna y el carácter de la ciudadanía permanecen en disputa con derechos precarios y vulnerables, entre ellos el acceso a y el fortalecimiento de la educación; sí existe un número de estudios importante sobre el conflicto armado y paz en la Orinoquía (Ramírez y Vidal, 2003) generados desde IES de los centros urbanos principales.

Un fenómeno similar se presenta en la región de la Amazonía, en la que la productividad general de los grupos es muy baja y el porcentaje de producción sobre conflicto armado y paz es aún menor (Trujillo Quintero, Losada Cubillos y Rodríguez Zambrano, 2017). El actual conflicto colombiano ha tenido en la región amazónica una expresión particular - la tendencia a los conflictos en los nuevos territorios que se van integrando a la nación se acentúa a medida que avanza la diferenciación social en el interior de la frontera (González, 2002) - que ha sido poco estudiada y analizada (Peña Chivata, Sierra Zamora y Hoyos Rojas, 2019; Zárate, 2015). Por el contrario, la concentración de producción científica en temas de paz se agrupa en la región Andina, debido a la mayor cantidad de IES en esta región. El pensamiento y las mediciones centralistas amplían y profundizan la brecha entre las universidades de las grandes capitales con respecto a las que desarrollan su accionar en las regiones y localidades (Bejarano Alzate, 2015).

Adicionalmente, las IES privadas (lideradas por la Pontificia Universidad Javeriana sede Bogotá, la Universidad de los Andes y la Corporación Región en Medellín) producen en conjunto más que las públicas (la Universidad Nacional de Colombia sede Bogotá presenta el mayor número de producción tanto para las IES públicas como para las privadas, siendo el único caso) en los tres tipos de publicaciones analizadas, lo que revela un centralismo en la producción de conocimiento en estas áreas de estudio. Esta tendencia, por su naturaleza misma, refleja posiciones, intereses y visiones individuales que sitúan el conocimiento en lugares de privilegio, situación que conlleva, en muchos casos, el desconocimiento de las regiones y los centros de pensamiento de la periferia. Las periferias tienen marcadas diferencias de desarrollo y 
cultura, por lo cual requieren respuestas diversas en relación con su situación para cerrar la brecha que las excluye de las oportunidades (Bejarano Alzate, 2015).

Sin que sea objeto de este estudio identificar las consecuencias de la producción de nuevo conocimiento para los pobladores y víctimas de las regiones periféricas, es evidente que la producción centralizada toma como objeto de estudio los problemas sociales, económicos y políticos de las zonas geográficas que han sufrido el conflicto armado. Como argumenta Salas Salazar (2015), la dimensión territorial no ha aparecido en los estudios relacionados con el conflicto armado y la violencia en Colombia para la comprensión de la dinámica de los territorios, siendo escasos los trabajos relacionados con esta dimensión como se observa en los resultados presentados anteriormente. Esta relación entre el centro productor y la periferia como objeto de estudio se enmarca en la dinámica geohistórica y geopolítica en la que ha estado situado el conocimiento.

Como se ha mostrado anteriormente, las áreas de conocimiento en ciencias sociales se destacan sobre las demás en lo que se refiere a la generación de producción científica en temas de paz, violencia y conflicto armado. Los resultados del Informe definitivo de convocatoria para indexación de revistas científicas colombianas especializadas (Convocatoria 768 de 2016) muestran que el área que presentó mayor participación, con el 45\%, fue la de ciencias sociales (Colciencias, 2017).

Al lado de las ciencias sociales, un área de conocimiento que incluye un número importante de publicaciones relacionadas con conflicto el armado y la paz son las ciencias agrarias. Dado que Colombia es un país agrícola, los investigadores de esta área se han enfocado en la comprensión de la dinámica del desarrollo rural y los orígenes de la violencia en el país, tema resaltado en el informe de la Comisión Histórica del Conflicto y sus Víctimas (2015).

Ahora bien, volviendo a las ciencias sociales, el eje central de la producción investigativa se encuentran las siguientes categorías: reparaciones, revisión del acuerdo, derechos humanos, desarrollo económico y social y grupos paramilitares, todas ellas desde la óptica de las víctimas del conflicto. En consecuencia, el interés de las investigaciones se dirige hacia la comprensión del desarrollo del conflicto armado desde una perspectiva humanista. 
La reconciliación, como principal eje de discusión en la generación de conocimiento desarrollada por los grupos de investigación, presenta alcances importantes para la comprensión de los fenómenos sociales. En palabras de Turriago Rojas (2016), para lograr procesos de reconciliación estables y duraderos, es necesario el diálogo sincero y honesto, que cree puentes, muestre esperanzas, acorte distancias y prevenga conflictos, poniendo en primer lugar las vivencias y experiencias que se generan en el territorio nacional y regional.

\section{PERSPECTIVAS EN INVESTIGACIÓN SOBRE CONFLICTO ARMADO Y PAZ: INTERPRETACIONES FINALES}

La prolongada y profunda transición en el contexto mundial ha provocado en las ciencias sociales nuevas maneras de mirar los fenómenos sociales, lo que se une a la crisis relativa, señalada en líneas anteriores, de los paradigmas convencionales (Leal Buitrago, 2013). La dinámica de producción científica desde la geopolítica del conocimiento es resultado de una interacción compleja entre múltiples factores, uno de los más determinantes tiene que ver con los principales hechos históricos sobre conflicto armado y los avances en la consecución de la paz en Colombia.

En este sentido, al igual que lo han hecho Montoya Arango, García Sánchez y Ospina Mesa (2014) se ha reflexionado aquí sobre las implicaciones que tiene la geopolítica, problematizando la relación entre territorio y producción de conocimiento. Es así como las ciencias sociales y sus múltiples disciplinas han creado una fuerte relación entre el conflicto armado y el desarrollo de su quehacer científico. Para otras áreas del conocimiento, tal relación ha llegado de forma tardía a sus programas académicos y se ha implementado, más bien, de forma instrumental: en el ámbito asistencial, de cooperación y de política pública.

Desde la academia, los investigadores de diferentes ámbitos han iniciado reflexiones acerca de las políticas de medición de producción de Colciencias, que delimitan el desarrollo natural de la investigación al ejercer presión con el "publica o perece". De esta forma, la producción sobre conflicto y paz ha encontrado nichos alejados de los centros académicos como es el caso de los múltiples informes del CNMH, que han abordado desde perspectivas investigativas y divulgativas la mayoría de los temas que se proponen en este estudio. Este tipo de producción permitirá en un futuro plantearse nuevos mapas de 
producción y de reflexión en cuanto a la incidencia de la geopolítica del conocimiento en los escenarios vinculados a los centros de pensamiento y en los sesgos que presenta el estudio del conflicto armado y la paz, ya sea desde la academia o desde los centros constituidos por mandato gubernamental.

Como expresan Polo Blanco y Gómez Betancur (2019) no hay centro sin periferia; por lo tanto, pensar el conocimiento y su historia permanece integrado al desarrollo propio del sistema-mundo. El despliegue mismo de los conocimientos sobre violencia y paz en Colombia viene configurado y jerarquizado por las determinaciones geopolíticas, geoeconómicas y geoculturales de la matriz imperial-colonial. De esta manera, los estudios bibliométricos no sólo deben constituirse como recuentos anuales de trabajos en revistas o bases de datos determinadas, sino que deben explorar la racionalidad técnico-instrumental en la que se definen, así como los alcances que están mediados por la intención y trayectoria de quienes los confeccionan (Hidalgo Dattwyler, Paulsen Espinoza y Alvarado Peterson, 2017).

Definitivamente, la producción sobre conflicto armado y paz en Colombia es un campo fértil que parece no agotarse. La pluralidad de temas y la diversidad de enfoques teóricos han contribuido a situar a los actores del conflicto y al hecho social, político y económico de la violencia en el centro del conocimiento, siendo esta su mayor fortaleza. A pesar de ello, falta avanzar en comprender desde áreas económicas, jurídicas y médicas los impactos que el conflicto armado ha tenido sobre la sociedad colombiana, el cual es uno de los mayores retos para los estudios de la violencia.

La posibilidad crítica de este trabajo estuvo en explorar la producción científica de una realidad social nacional, lo que deja preguntas abiertas, ¿hasta dónde la producción de conocimiento sobre violencia y paz en Colombia puede desligarse de esta relación de ejes centro-periferia?, ¿cómo lo producido desde los centros llega a los círculos de la periferia?, y ¿cuáles son las temáticas de investigación que permitirán el desarrollo e implementación de los puntos refrendados del acuerdo de paz en los territorios?.

Por tanto, la calidad de la producción científica de las periferias debe evaluarse en virtud de su potencial transformador para los territorios desde donde se produce. Finalmente, la sociedad colombiana ha 
sufrido una metamorfosis, un antes y un después que han permitido mirar el fenómeno social violento y la construcción de paz desde ejes decisivos que reconocen que el saber es la gente y el espacio que esta habita, más que un mero depósito de información sobre el cual se realizan análisis, "siendo los pobladores más bien agentes activos con quienes se interactúan y se producen conjuntamente conocimientos desde sus territorios" (Montoya Arango, García Sánchez y Ospina Mesa, 2014:193).

(Recibido el 10 de agosto de 2019)

(Reenviado el 16 de abril de 2020)

(Aprobado para su publicación el 16 de septiembre de 2020)

\section{NOTAS}

1. Algunos autores como Salas Salazar (2016) y Sánchez y Meertens (1983) establecen el inicio de este periodo en 1948 como la génesis de la primera violencia debido a que en muchas de las regiones en las que se registraron niveles de violencia persisten hoy en día. Asimismo, consideran el año 1958, terminada la dictadura del General Gustavo Rojas Pinilla, como el inicio de un segundo periodo de violencia caracterizada por el fenómeno del bandolerismo.

2. Ríos Sierra (2016) considera que la etapa de polarización de la confrontación se extiende hasta 2004, ya que una vez terminados los fallidos diálogos de paz con las FARC en el Caguán, transcurren los dos años de mayor confrontación de la violencia.

3. De acuerdo con Jaramillo Marín (2014), más que un diagnóstico investigativo, a la Comisión de Estudio sobre la Violencia se le pidió una propuesta para superar todos los tipos de violencia, por lo que las recomendaciones eran lo esencial.

4. La metodología para la producción de informes es el estudio de casos emblemáticos que buscan establecer y esclarecer las causas de los fenómenos de violencia, para conocer la verdad y contribuir a evitar la repetición de los hechos. Disponible en: http:/ /www. centrodememoriahistorica.gov.co.

5. La comisión fue conformada por doce expertos y dos relatores, y su informe Contribución al entendimiento del conflicto armado en Colombia consta de doce ensayos y dos relatorías. Disponible en: https:/ / www.mesadeconversaciones.com.co/sites/default/files/Informe $\% 20$ Comisi_n $\% 20$ Hist_rica $\% 20$ del $\% 20$ Conflicto $\% 20 \mathrm{y} \% 20$ sus $\% 20$ V_ctimas. $\% 20$ La\%20Habana\%2C\%20Febrero\%20de\%202015.pdf.

6. Este artículo utilizará la denominación Colciencias en lugar de Minciencias debido a que era la vigente en el momento de la realización de la investigación. Asimismo, los documentos utilizados como referencia fueron emitidos por dicha institución.

7. Convocatoria Nacional $n^{\circ} 833$ de Colciencias para el reconocimiento y medición de grupos de investigación, desarrollo tecnológico o de innovación y para el reconocimien- 
to de investigadores del Sistema Nacional de Ciencia, Tecnología e Innovación - SNCTeI, 2018. Disponible en: https://www.colciencias.gov.co/convocatorias/investigacion/ convocatoria-nacional-para-el-reconocimiento-y-medicion-grupos-0.

8. Ver: Modelo de medición de grupos de investigación, desarrollo tecnológico e innovación (Colciencias, 2018) para conocer los parámetros de categorización. 


\section{REFERENCIAS}

AGNEW, John. (2015), "The geopolitics of knowledge about world politics: a case study in U.S. hegemony". En: P. Meusburger; D. Gregory; L. Suarsana (eds.), Geographies of knowledge and power. London: Springer, pp. 235-246.

ÁLVAREZ CALDERÓN, Carlos Enrique; RODRÍGUEZ BELTRÁN, Carlos Andrés. (2018), "Ecosistemas criminales: hábitats para la convergencia y la globalización desviada". Revista Científica General José María Córdova [online], vol. 16, nº 24 [24-02-2020], pp. 1-30. Disponible en: https://doi.org/10.21830/19006586.352.

APONTE, Andrés; BENAVIDES, Javier. (2016), “Las Farc y las organizaciones comunitarias en San Andrés de Tumaco: desafíos territoriales ante una eventual implementación de los Acuerdos de La Habana". Revista Controversia, n² 206, pp. 97-150.

BARRERO VELÁSQUEZ, María Teresa. (2011), “Disertaciones sobre la evolutiva injerencia de la Corte Penal Internacional en Colombia". Revista Científica General José María Córdova [online], vol. 9, no 9 [16-11-2019], pp. 117-145. Disponible en: https:/ /doi. org/10.21830/19006586.248.

BECHARA GÓMEZ, Eduardo. (2012), ¿Prolongación sin solución? Perspectivas sobre la guerra y la paz en Colombia. Bogotá D.C.: Universidad Externado de Colombia.

BEJARANO ALZATE, Jaime. (2015), "Calidad educativa centralizada o descentralizada". Sophia, vol. 11, n 2, pp. 113-114.

BEJARANO, Jesús. (1985), "Historiografía de la violencia en Colombia”. En: M. Cárdenas (ed.), Once ensayos sobre la violencia. Bogotá D.C.: Fondo Editorial CEREC, pp. 209-258.

BERMÚDEZ QUINTANA, Elba María et al. (2018), "Perpetuación de violencias verbal y psicológicas en las relaciones afectivas y de familia en adolescentes de Cali". Revista Científica General José María Córdova [online], vol. 16, nº 21 [10-10-2019], pp. 61-80, 2018. Disponible en: https:/ / doi.org/10.21830/19006586.312.

BERMÚDEZ TAPIA, Manuel Alexis; SIERRA ZAMORA, Paola Alexandra; KARÁN BENITEZ, Andrés Eduardo. (2020a), El Estado ante emergencias sociales. Bogotá D.C.: Sello Editorial ESMIC. Disponible en: https://doi.org/10.21830/9789585284869.

BERMÚDEZ TAPIA, Manuel Alexis; SIERRA ZAMORA, Paola Alexandra; FERNANDEZ OSORIO, Andrés Eduardo. (2020b), La Tutela de derechos individuales y colectivos en el Estado de derecho. Bogotá D.C.: Sello Editorial ESMIC. Disponible en: https:/ /doi. org/10.21830/9789585284845.

BETANCOURT ECHEVERRY, Darío. (1991), “Los cinco focos de la mafia colombiana (19681988). Elementos para una historia". Folios [online], no 2 [12-11-2019], pp. 13-30. Disponible en: https:/ / doi.org/10.17227/01234870.num2.folios5333.

BLAIR TRUJILLO, Elsa. (2009), “Aproximación teórica al concepto de violencia: avatares de una definición". Política y Cultura, n³2, pp. 9-33.

CABRERA CABRERA, Leidy Johana et al. (2018), "Sobre relatos y memoria: una reflexión sobre el conflicto armado colombiano desde la historia militar". Revista Científica General José María Córdova [online], vol. 16, nº 24 [11-05-2019], pp. 177-201. Disponible en: https:/ / doi.org/10.21830/19006586.363. 
CAIRO, Heriberto et al. (2018), "Territorial peace: the emergence of a concept in Colombia's peace negotiations". Geopolitics [online], vol. 23, n 2 [23-02-2019], pp. 464-488. Disponible en: https://doi.org/10.1080/14650045.2018.1425110.

CALDERÓN ROJAS, Jonathan. (2016), "Etapas del conflicto armado en Colombia: hacia el posconflicto". Latinoamérica. Revista de Estudios Latinoamericanos, nº 62, pp. 227-257.

CARTAGENA, Laura. (2016), "Los estudios de la violencia en Colombia antes de la violentología". Diálogos. Revista Electrónica de Historia [online], vol. 17, no 1 [10-10-2019], pp. 63-88. Disponible en: https://doi.org/10.15517/dre.v17i1.18103.

CATATUMBO, Pablo. (1990), “La doctrina de la seguridad nacional: el principal obstáculo para la paz". Revista Javeriana, vol. 118, n 590, pp. 308-312.

CENTRO NACIONAL DE MEMORIA HISTÓRICA. (2013), ¡Basta Ya! Colombia: Memorias de guerra y dignidad. Bogotá D.C.: CNMH.

CHAVARRO MIRANDA, Fernando; GRAUTOFF LAVERDE, Manfred; RIAÑO CRUZ, Julián David. (2017), “Modelo de crecimiento económico y gasto público focalizado en seguridad: enfoque desde la estrategia militar en Colombia (2002-2009)". Revista Científica General José María Córdova [online], vol. 15, no 20 [12-08-2019], pp. 27-45. Disponible en: https://doi.org/10.21830/19006586.174.

COLCIENCIAS. (2016), Política nacional para mejorar el impacto de las publicaciones científicas nacionales departamento administrativo de ciencia, tecnología e innovación. Bogotá. D.C.: Colciencias. Disponible en: https://www.colciencias.gov.co/sites/default/files/upload/ noticias/120816-vfpolitica_publindex_2.0_og_ao_miv.pdf.

. (2017), Informe de la Convocatoria para Indexación de Revistas Científicas Colombianas Especializadas-Publindex. Bogotá D.C.: Colciencias. Disponible en: https:/ /www.colciencias.gov.co/sites/default/files/informe-resultados-publindex.pdf.

. (2018), Convocatoria nacional para el reconocimiento y medición de grupos de investigación, desarrollo tecnológico o de innovación y para el reconocimiento de investigadores del sistema nacional de ciencia, tecnología e innovación-SNCTeI 2018. Bogotá D.C.: Colciencias. Disponible en: https://colciencias.gov.co/sites/default/files/upload/convocatoria/4._anexo_1._documento_conceptual_del_modelo_de_reconocimiento_y_medicion_de_grupos_de_investigacion_2018.pdf.

CORCHUELO-RODRÍGUEZ, Camilo Alejandro; PATACÓN-RUIZ, Ingrid Paola; PIZA-AMADO, Karol. (2020), “Revistas de Ciencias Sociales en el modelo de clasificación de Publindex: prospectiva de la convocatoria No. 830 del 2018 en la fase III. Impacto de la revista científica". Revista Interamericana de Investigación, Educación y Pedagogía, vol. $13, \mathrm{n}^{\circ} 1$, pp. 137-155.

CORCIONE NIETO, María Antonieta; CABRERA CABRERA, Leidy Johana; LATORRE ROJAS, Edna Jackeline. (2020), Las mujeres militares en el Ejército Nacional de Colombia. Estudios transversales de su participación en las filas. Bogotá D.C.: Sello Editorial ESMIC. Disponible en: https://doi.org/10.21830/9789585318304.

CUBIDES CÁRDENAS, Jaime Alfonso et al. (2019), “Terrorism by the FARC-EP and public policies oriented towards national security in Colombia during 1990-2000". Revista Científica General José María Córdova [online], vol. 17, nº 26 [10-11-2019], pp. 309-325. Disponible en: https://doi.org/10.21830/19006586.404. 
CUBIDES CÁRDENAS, Jaime Alfonso; GARAY ACEVEDO, Claudia Patricia. (2013), “Hacia la construcción de un estado del arte de la seguridad y defensa nacional en Colombia". Revista Científica General José María Córdova [online], vol. 11, nº 11 [08-09-2019], pp. 81-98. Disponible en: https://doi.org/10.21830/19006586.205.

CUBIDES CÁRDENAS, Jaime Alfonso; SIERRA ZAMORA, Paola Alexandra. (2020), Seguridad, Justicia y Derechos Humanos: La superación del conflicto colombiano y su dimensión internacional. Bogotá D.C.: Sello Editorial ESMIC. Disponible en: https://doi. org/10.21830/9789585287860

DEAS, Malcom; GAITÁN, Fernando. (1995), Dos ensayos especulativos sobre la violencia en Colombia. Bogotá D.C.: Tercer Mundo Editores.

ECHANDÍA CASTILLA, Camilo. (2000), “El conflicto armado colombiano en los años noventa: cambios en las estrategias y efectos económicos". Colombia Internacional [online], no 49-50 [14-05-2019], pp. 117-134. Disponible en: https: / /doi.org/10.7440/colombiaint $49-50.2000 .06$.

ECHEVERRI, Marcela. (2001), "Historia de las ciencias Sociales en Colombia: un proyecto crítico. Ciencia política, teoría política y construcción de la idea de democracia (19892001)”. Revista Colombia Ciencia y Tecnología, vol. 19, n 4, pp. 9-21.

ESTUPIÑÁN ACHURY, Liliana. (2018), “¿Es posible la paz territorial en Colombia? A propósito del Acuerdo Final de Paz entre Gobierno y Grupo FARC". Diritto Pubblico Comparato ed Europeo [online], vol. 20, n 1, pp. 127-142. Disponible en: https:/ /doi. org/10.17394/89141.

FERNANDEZ-OSORIO, Andres Eduardo. (2019a), "La implementación del acuerdo de paz con las FARC-EP: un estudio comparado desde la experiencia internacional". Análisis Político [online], vol. 32, no 95 [16-11-2019], pp. 104-124. Disponible en: https:/ /doi. org/10.15446/anpol.v32n95.80977.

. (2019b), “Editorial: Tendencias en la clasificación de revistas indexadas colombianas en ciencias sociales". Revista Científica General José María Córdova [online], vol. 17, nº 26 [16-11-2019], pp. 215-226. Disponible en: https:/ / doi.org/10.21830/19006586.437.

FLÓREZ CARRANZA, Favio Andrés. (2018), “Nociones de calidad e impacto: el lugar de las revistas indexadas de ciencias jurídicas en el nuevo sistema colombiano de competitividad, ciencia, tecnología e innovación". Vniversitas [online], vol. 67, nº 137 [23-09-2019], pp. I-XIV. Disponible en: https://doi.org/10.11144/Javeriana.vj137.ncei.

FRANCO MONGUA, Javier Francisco; VILLALBA CUÉLLAR, Juan Carlos; GONZÁLEZ SERRANO, Andrés. (2015), "El (que) hacer de las ciencias sociales, el desarrollo y las políticas públicas en Colombia""'. Revista Prolegómenos Derechos y Valores [online], vol. 18, no 36 [03-06-2019], pp. 9-13. Disponible en: https://doi.org/10.18359/dere.930.

GARAY ACEVEDO, Claudia Patricia; GUECHA, Andrea del Pilar Pérez. (2018), “Los derechos humanos en Colombia". Revista Científica General José María Córdova [online], vol. 16, no 23 [14-08-2019], pp. 83-105. Disponible en: https://doi.org/10.21830/19006586.307.

GARCÍA JURADO, Mayra Alejandra. (2018), “Contribución de las mujeres en las revistas de sociología colombianas 1959-2000". Campos en Ciencias Sociales [online], vol. 6, nº 1 [2704-2019], pp. 73-90. Disponible en: https://doi.org/10.15332/s2339-3688.2018.0001.03. 
GONZÁLEZ, Fernán. (2002), “Colombia entre la guerra y la paz. Aproximación a una lectura geopolítica de la violencia colombiana". Revista Venezolana de Economía y Ciencias Sociales, vol. 8, n 2, p. 13-49.

GRANADA, Camilo; ROJAS, Leonardo. (1995), "Los costos económicos del conflicto armado en Colombia: 1990-1994". Revista de Planeación y Desarrollo, vol. 26, nº 4, p. 119-151.

GUANUMEN, Merly. (2015), “Dinámicas de la guerra, desafíos para la paz. La experiencia de Colombia". Ciudad Paz-ando [online], vol. 8, no 1 [29-03-2019], pp. 40. Disponible en: https://doi.org/10.14483/udistrital.jour.cpaz.2015.1.a03.

GUERRA, María del Rosario; PLATA, Juan José. (2005), “Estado de la investigación sobre conflicto, posconflicto, reconciliación y papel de la sociedad civil en Colombia". Revista de Estudios Sociales [online], nº 21 [14-05-2019], pp. 81-92. Disponible en: https://doi. org/10.7440/res21.2005.07.

GUTIÉRREZ LOAIZA, Alderid. (2012), “Negociaciones de paz en Colombia, 1982-2009. Un estado del arte". Estudios Políticos, n 40, pp. 175-200.

GUTIERREZ LÓPEZ, William. (1999), “Las políticas de paz y los procesos de negociación en Colombia. Breve balance y perspectivas". Convergencia. Revista de Ciencias Sociales, vol. $6, \mathrm{n}^{\circ} 19$, pp. 245-274.

GUZMÁN, German; FALS BORDA, Orlando; UMAÑA, Eduardo. (1962), La Violencia en Colombia. Estudio de un proceso social. Bogotá D.C.: Carlos Valencia Editores.

HENDERSON, James. (1984), Cuando Colombia se desangró. Un estudio de la violencia en la metrópoli y la provincia. Bogotá D.C.: El Áncora Editores.

HIDALGO DATTWYLER, Rodrigo Alejandro; PAULSEN ESPINOZA, Alex Patricio; ALVARADO PETERSON, Voltaire Christian. (2017), "Bibliometrías de las luchas urbanas por la vivienda: Delineando las geografías críticas del conocimiento". ACME: An International Journal for Critical Geographies, vol. 16, nº 4, pp. 653-686.

HIGUITA, Oto. (2014), "Los diálogos de La Habana y las perspectivas de una paz duradera en Colombia". El Ágora, vol. 14, n² 2, pp. 487-515.

JARAMILLO MARÍN, Jefferson. (2014), Pasados y presentes de la violencia en Colombia. Bogotá D.C.: Pontificia Universidad Javeriana.

JASANOFF, Sheila; WYNNE, Brian. (1998), "Science and decisionmaking”. En: S. Rayner; E. Malone (eds.), Human Choice and Climate Chance, Volumen 1. Columbus: Battelle Press, pp. 1-112.

LAHSEN, Myanna. (2009), "A science-policy interface in the global south: the politics of carbon sinks and science in Brazil". Climatic Change [online], vol. 97, n 3-4 [27-04-2019], pp. 339-372. Disponible en: https://doi.org/10.1007/s10584-009-9610-6.

LEAL BUITRAGO, Francisco. (2013), La profesionalización de las ciencias sociales en Colombia. Bogotá D.C.: Universidad de los Andes.

LEDERACH, Angela J. (2017), “The campesino was born for the campo: a multispecies approach to territorial peace in Colombia". American Anthropologist [online], vol. 119, $\mathrm{n}^{\circ}$ 4 [25-03-2019], pp. 589-602, 2017. Disponible en: https://doi.org/10.1111/aman.12925. 
MARTÍNEZ LAZCANO, Alfonso Jaime; PÉREZ, Eduardo Santiago; CUBIDES CÁRDENAS, Jaime Alfonso. (2015), "Implicaciones del Control de Convencionalidad: cumplimiento de la Sentencia Radilla Pacheco versus México y el caso de la masacre de Santo Domingo versus Colombia". Revista Científica General José María Córdova [online], vol. 13, n 15 [28-08-2019], pp. 115-141. Disponible en: https://doi.org/10.21830/19006586.19.

MEDINA GALLEGO, Carlos. (1990), Autodefensas, paramilitares y narcotráfico en Colombia. Origen, desarrollo y consolidación: el caso Puerto Boyacá. Bogotá, D.C.: Editorial Documentos Jurídicos.

(2005), “La economía de guerra paramilitar: una aproximación a sus fuentes de financiación". Análisis Político, n 53, pp. 77-87.

MELAMED VISBAL, Janiel David. (2014), “Del conflicto al posconflicto en el contexto colombiano". Revista de la Universidad de La Salle, $\mathrm{n}^{\circ}$ 63, pp. 57-73.

MENA ORTEGA, Julie. (2016), "Pensar la paz... solo cuando tenga la tierra". Revista Controversia, $\mathrm{n}^{\circ} 206$, pp. 293-326.

MIGNOLO, Walter. (2003), “Los estudios culturales: geopolítica del conocimiento y exigencias/necesidades institucionales". Revista Iberoamericana, vol. LXIX, n² 203, pp. 401-415.

MONTOYA ARANGO, Vladimir; GARCÍA SÁNCHEZ, Andrés; OSPINA MESA, Cesar. (2014), "Andar dibujando y dibujar andando: cartografía social y producción colectiva de conocimientos". Nómadas, n 40, pp. 191-205.

NASI, Carlo; RETTBERG, Angelika. (2005), “Los estudios sobre conflicto armado y paz: un campo en evolución permanente". Colombia Internacional [online], $\mathrm{n}^{\circ} 62$ [26-09-2019], pp. 64-85. Disponible en: https://doi.org/10.7440/colombiaint62.2005.04.

NIÑO GONZÁLEZ, César Augusto. (2016), “El narcotráfico mutante: nueva perspectiva de análisis del fenómeno en Colombia". Revista Científica General José María Córdova [online], vol. 14, no 18 [23-09-2019], pp. 113-124. Disponible en: https://doi. org/10.21830/19006586.45.

OFICINA DEL ALTO COMISIONADO PARA LA PAZ. (2015), Informe de la Comisión Histórica del Conflicto y sus Víctimas. Bogotá D.C.: OACP. Disponible en: http://www.altocomisionadoparalapaz.gov.co/Documents/informes-especiales/resumen-informe-comision-historica-conflicto-victimas/index.html.

OLAVE, Giohanny. (2014), “Aproximaciones retóricas al conflicto armado colombiano: una revisión bibliográfica". Forma y Función [online], vol. 27, no 1 [27-04-2019], pp. 155-197. Disponible en: https://doi.org/10.15446/fyf.v27n1.46951.

OQUIST, Paul. (1978), Violencia, conflicto y política en Colombia. Bogotá D.C.: Instituto de Estudios Colombianos.

ORTIZ SARMIENTO, Carlos. (1992), “Los estudios sobre la violencia en las tres últimas décadas". Boletín Socioeconómico, nº 24/25, pp. 47-52.

. (1994), "Historiografía de la violencia". En: B. Tovar Zambrano (ed.), La historia al final del milenio ensayos de historiografía colombiana y latinoamericana, Volumen 1. Bogotá D.C.: Universidad Nacional de Colombia, pp. 371-442. 
PALACIO, German; ROJAS, Fernando. (1990), “Empresarios de la cocaína, parainstitucionalidad y flexibilidad del régimen político colombiano: narcotráfico y contrainsurgencia". En: G. Palacio (ed.), La irrupción del paraestado. Ensayos sobre la crisis colombiana. Bogotá D.C.: ILSA-CEREC, pp. 69-104.

PALACIOS, Marco. (1999), “La solución política al conflicto armado, 1982-1997”. En: A. Camacho Guizado; F. Leal Buitrago (eds.), Armar la paz es desarmar la guerra: herramientas para lograr la paz. Bogotá D.C.: Instituto de Estudios Políticos y Relaciones Internacionales.

PALMA MORALES, Oscar. (2012), “La discusión sobre la relación entre antinarcóticos y contrainsurgencia: ideas para la construcción de un marco teórico diferente". Revista Científica General José María Córdova [online], vol. 10, no 10 [09-10-2019], pp. 49-62. Disponible en: https://doi.org/10.21830/19006586.226.

PECAUT, Daniel. (1991), “Colombia: violencia y democracia”. Análisis Político, n 13, pp. 35-49. . (1997), "Presente, pasado y futuro de la violencia". Análisis Político, n 30, pp. 3-36.

. (1999), "Configuraciones del espacio, el tiempo y la subjetividad en un contexto de terror: el caso colombiano". Revista Colombiana de Antropología, nº 35, pp. 8-35.

. (2000), “Colombia: una paz esquiva”. Revista Colombiana de Sociología, vol. 5, nº 2, pp 15-48.

. (2008), "Las FARC: fuentes de su longevidad de la conservación de su cohesión". Análisis Político, n 63 , pp. 22-29.

PEÑA CHIVATA, Cipriano; SIERRA ZAMORA, Paola Alexandra; HOYOS ROJAS, Juan Carlos. (2019), "La política de fronteras de Colombia ante las nuevas amenazas de seguridad y defensa". Revista Científica General José María Córdova [online], vol. 17, n 28 [08-08-2019], pp. 773-795. Disponible en: https://doi.org/10.21830/19006586.473.

PEÑARANDA, Ricardo. (1987), “La guerra en el papel: balance de la producción sobre la violencia durante los años noventa". En: G. Sánchez; R. Peñaranda (eds.), Pasado y presente de la violencia en Colombia. Medellín: La Carreta Editores, pp. 34-46.

PIZARRO LEONGÓMEZ, Eduardo. (1987), “Movimiento guerrillero y proceso de Paz". Análisis Político, $\mathrm{n}^{\circ} 1$, pp. 109-112.

. (1988), “Una paz sin victorias: balance del proceso de Paz centroamericano". Análisis Politico, no 5, pp. 28-45.

. (1992), "Colombia: ¿hacia una salida democrática a la crisis nacional?". Análisis Político, $\mathrm{n}^{\circ} 17$, pp. 41-60.

POLO BLANCO, Jorge; GÓMEZ BETANCUR, Milany. (2019), “Modernidad y colonialidad en América Latina. ¿Un binomio indisociable? Reflexiones en torno a las propuestas de Walter Mignolo". Revista de Estudios Sociales, n 69, pp. 2-13.

QUERUBíN, Pablo. (2002), "Crecimiento departamental y violencia criminal en Colombia". Documentos CEDE, $\mathrm{n}^{\circ} 12$, pp. 1-49.

QUINTERO CORDERO, Sara Patricia. (2020), La Cooperación Internacional e Intervención en escenarios de posconflicto. Bogotá D.C.: Sello Editorial ESMIC. Disponible en: https:// doi.org/10.21830/9789585287808. 
RAMÍREZ, María Constanza; VIDAL, Liliana. (2003), Conflicto social armado y efectos ambientales en la Orinoquia. Bogotá D.C.: Foro Nacional Ambiental.

RAMÍREZ, William. (1990), Estado, violencia y democracia. Bogotá D.C.: Universidad Nacional de Colombia.

RAMÍREZ-OROZCO, Mario. (2014), “Aproximación bibliográfica a la construcción de la paz en Colombia". Revista Universidad de La Salle, n 63, pp. 23-43.

REPUBLICA DE COLOMBIA. (1991), Decreto No. 585 Por el cual se crea el consejo nacional de ciencia y tecnología, se reorganiza el instituto colombiano para el desarrollo de la ciencia y la tecnología -Colciencias- y se dictan otras disposiciones. Bogotá D.C.: Imprenta Nacional.

RETTBERG, Angelika. (2010), "Introducción: de las violencias y el conflicto armado a la construcción de paz: el Departamento de Ciencia Política de la Universidad de los Andes amplía su agenda de investigación". En: A. Rettberg (ed.), Conflicto armado, seguridad y construcción de paz en Colombia. Bogotá D.C.: Universidad de los Andes, pp. 19-42.

REYES POSADA, Alejandro. (1991), “Paramilitares en Colombia: contexto, aliado y consecuencias". Análisis Político, vol. 2, n 12, pp. 35-42.

; BEJARANO, Ana María. (1988), “Conflictos agrarios y luchas armadas en la Colombia contemporánea: una visión geográfica". Análisis Político, n 5, pp. 6-27.

RICHARD, Nelly. (2002), Saberes académicos y reflexión crítica en América Latina. Buenos Aires: CLACSO.

RÍOS SIERRA, Jerónimo. (2017), “Determinantes geográfico-políticos de la acción violenta guerrillera: un análisis de la concurrencia regional de guerrillas y paramilitares en el conflicto colombiano". Revista Española de Ciencia Política [online], no 44 [12-11-2019], pp. 121-149. Disponible en: https://doi.org/10.21308/recp.44.05.

(2016), "La periferialización del conflicto armado colombiano, 2002-2014". Geopolítica(s). Revista de Estudios sobre Espacio y Poder [online], vol. 7, n 2 [08-08-2019], pp. 251-275. Disponible en: https://doi.org/10.5209/geop.52270.

; GAGO ANTÓN, Egoitz. (2018), “Realidades y desafíos de la paz territorial en Colombia". Papers: Revista de Sociología, vol. 103, n² 2, pp. 281-302.

RONDEROS, Maria Teresa. (2014), Guerras Recicladas. Una historia periodística del paramilitarismo en Colombia. Bogotá D.C.: Aguilar.

RUEDA, Maria. (2008), “Nación y narración de la violencia en Colombia (De la historia a la sociología)". Revista Iberoamericana, vol. LXXIV, nº 223, pp. 345-359.

RUIZ OCAMPO, Edwin; ECHEVERRY MARTÍNEZ, María Alejandra. (2017), La institucionalización de la investigación para la paz en Colombia. Cali: Universidad del Valle.

SALAS SALAZAR, Luis Gabriel. (2015), “Lógicas territoriales y relaciones de poder en el espacio de los actores armados: un aporte desde la geografía política al estudio de la violencia y el conflicto armado en Colombia, 1990-2012". Cuadernos de Geografía: Revista Colombiana de Geografía, vol. 24, n 1, pp. 157-172.

. (2016), "Conflicto armado y configuración territorial: elementos para la consolidación de la paz en Colombia". Revista Bitácora Urbano Territorial, vol. 26, n² 2, pp. 47-57. 
SÁNCHEZ, Fabio; DÍAZ, Ana. (2005), Los efectos del conflicto armado en el desarrollo social colombiano, 1990-2002. Bogotá D.C.: Universidad de los Andes.

SÁNCHEZ, Gonzalo. (1987), “Los estudios sobre la violencia: balance y perspectivas",. En: G. Sánchez; R. Peñaranda (eds.), Pasado y presente de la violencia en Colombia. Medellín: La Carreta Editores, pp. 17-32.

; MEERTENS, Donny. (1983), Bandoleros, gamonales y campesinos. Bogotá D.C.: El Áncora Editores.

SÁNCHEZ, Jairo. (2014), “Estudios de violencia y conflicto: aproximación a un análisis transdisciplinar de la violencia política". Comunicación, Cultura y Política [online], vol. 5, n 1 [30-09-2019], pp. 49-70. Disponible en: https://doi.org/10.21158/21451494.N1.2014.1284.

SEGATO, Rita Laura. (2015), Geopolítica del conocimiento: universidad y país. Algunos ejemplos desde Brasil. Brasilia: Universidad de Brasilia.

SEMANA. (2018), "Publindex, 'la purga' de las revistas universitarias". Semana [online]. Disponible en: https:/ / www.semana.com/educacion/articulo/forma-para-que-las-revistas-cientificas-sean-indexadas/557701.

SERJE, Margarita. (2006), "Geopolítica de la ocupación territorial de la nación en Colombia". Gestión y Ambiente, vol. 9, n³, pp. 21-27.

SHAPIN, Steven. (1998), "Placing the view from nowhere: historical and sociological problems in the Location of Science". Transactions of the Institute of British Geographers [online], vol. 23, $\mathrm{n}^{\circ} 1$ [27-04-2019], pp. 5-12. Disponible en: https://doi.org/10.1111/j.00202754.1998.00005.x.

SIERRA ZAMORA, Paola Alexandra. (2020), El conflicto armado, el acuerdo de paz y la justicia transicional. El caso colombiano. Bogotá D.C.: Grupo Editorial Ibáñez.

; BERMÚDEZ TAPIA, Manuel Alexis. (2020), Evaluación Jurídica de la Seguridad y Defensa nacional como política de Estado. Bogotá D.C.: Escuela Superior de Guerra "General Rafael Reyes Prieto".

SIERRA ZAMORA, Paola Alexandra; BERMÚDEZ TAPIA, Manuel Alexis; KARÁN BENITEZ, Cesar Alberto. (2020a), Las consecuencias del conflicto armado interno en el posacuerdo colombiano. Bogotá D.C.: Sello Editorial ESMIC. Disponible en: https://doi. org/10.21830/9789585241480.

SIERRA ZAMORA, Paola Alexandra; BERMÚDEZ TAPIA, Manuel Alexis; ARANGOCALDERÓN, Ingrid Yuliana. (2020b), Elementos judiciales y procesales en contextos de cambios sociales. Bogotá D.C.: Sello Editorial ESMIC. Disponible en: https://doi.org/10.21830/9789585284883.

SIERRA ZAMORA, Paola Alexandra; BERMÚDEZ TAPIA, Manuel Alexis; PEDRAZA MARIÑO, Carolina. (2020c), Perspectivas en Derechos Humanos y Derecho Internacional Humanitario para el Ejército Nacional de Colombia. Bogotá D.C.: Sello Editorial ESMIC. Disponible en: https://doi.org/10.21830/9789585287884.

SOBERÓN, Ricardo. (2002), "El conflicto colombiano: entre lo geopolítico y lo humanitario". Agenda Internacional, vol. VIII, nº 17, pp. 89-101.

SOLANO, Nereida; CARABALLO, Nelson. (2015), "Sujeto docente y geopolítica del conocimiento en los espacios universitarios emergentes". Saber, vol. 27, nº 2, pp. 300-309. 
TORRIJOS RIVERA, Vicente; ABELLA OSORIO, Juan David. (2018), "El comportamiento de las FARC tras la firma de los acuerdos de La Habana". Revista Científica General José María Córdova [online], vol. 16, nº 24 [24-02-2019], pp. 31-60. Disponible en: https:/ /doi. org $/ 10.21830 / 19006586.342$.

TREJOS ROSERO, Luis. (2013), “Colombia: una revisión teórica de su conflicto armado". Revista Enfoques: Ciencia Política y Administración Pública, vol. 11, nº 18, pp. 55-75.

TRUJILLO, Edgar; BADEL, Martha. (1998), “Los costos económicos de la criminalidad y la violencia en Colombia: 1991-1996". Archivos de Macroeconomía, n. 76, p. 1-49.

TRUJILLO QUINTERO, Hernán Felipe; LOSADA CUBILLOS, Jhon Jairo; RODRÍGUEZ ZAMBRANO, Hernando. (2017), “Amazonia colombiana, petróleo y conflictos socioambientales". Revista Científica General José María Córdova [online], vol. 15, n 20 [30-06-2019], pp. 209-223. Disponible en: https://doi.org/10.21830/19006586.181.

TURRIAGO ROJAS, Daniel Guillermo. (2016), “Los procesos de paz en Colombia, camino ¿a la reconciliación?" Actualidades Pedagógicas [online], no 68 [03-06-2019], pp. 159-178. Disponible en: https://doi.org/10.19052/ap.3827.

URIBE, María Teresa. (2001), “Las soberanías en disputa: ¿conflicto de identidades o de derechos?". En: M. Uribe (ed.), Nación, ciudadano y soberano. Medellín: Corporación Región, pp. 249-270.

VALENCIA AGUDELO, Germán Darío. (2013), “Alternancias de la paz y la guerra en Colombia, 1978-2013". Debates, nº 64, pp. 44-53.

(2016), "Violencia, conflicto armado y proceso de paz en las dinámicas indagativas de las ciencias sociales y humanas en Colombia". Debates, nº 74, pp. 79-86.

VALENCIA AGUDELO, Germán Darío. (2017), “Un balance de los estudios sobre la paz negociada en Colombia". Estudios Políticos [online], no 50 [03-06-2019], pp. 203-2015. Disponible en: https://doi.org/10.17533/udea.espo.n50a11.

VALENCIA GUTIÉRREZ, Alberto. (2012), “La Violencia en Colombia de M. Guzmán, O. Fals y E. Umaña y las trasgresiones al Frente Nacional". Revista Colombiana de Sociología, vol. $35, \mathrm{n}^{\circ} 2$, pp. 15-33.

VARGAS PULIDO, William; GODOY ESTRELLA, Enit. (2013), “Impacto del gasto de la defensa en el crecimiento económico de Colombia en los últimos veinte años". Revista Científica General José María Córdova [online], vol. 11, no 11 [01-09-2019], pp. 227-257. Disponible en: https://doi.org/10.21830/19006586.212.

VELÁSQUEZ RIVERA, Edgar de Jesús. (2007), “Historia del paramilitarismo en Colombia”. Historia (São Paulo), vol. 26, nº 1, pp. 134-153.

VERA LUGO, Juan Pablo. (2015), “Antropología y estudios de la violencia en Colombia: en busca de una perspectiva crítica". Revista Colombiana de Antropología [online], vol. 51, $\mathrm{n}^{\circ} 1$ [27-04-209], pp. 245-269. Disponible en: https://doi.org/10.22380/2539472X.242.

VILLAMIZAR, Juan Carlos. (2018), “Elementos para periodizar la violencia en Colombia: dimensiones causales e interpretaciones historiográficas". Ciencia Política [online], vol. 13, no 25 [08-05-2019], pp. 173-192. Disponible en: https://doi.org/10.15446/cp.v12n25.65251. 
VILLARRAGA SARMIENTO, Álvaro. (2015). “Los procesos de paz en Colombia, 19822014: documento resumen". Bogotá D.C. Disponible en: http:/ / biblioteca.ucp.edu.co/ Descargas/core/documentos/2.pdf.

WALSH, Catherine. (2007), "Shifting the geopolitics of critical knowledge". Cultural Studies [online], vol. 21, nº 2-3, pp. 224-239. Disponible en: https://doi.org/10.1080/09502380601162530.

ZÁRATE, Carlos. (2015), “Estado, militares y conflicto en la frontera amazónica colombiana: referentes históricos para la interpretación regional del conflicto". Mundo Amazónico [online], vol. 6, n 1 [ [03-06-2019], pp. 73-96. Disponible en: https://doi.org/10.15446/ ma.v6n1.50059.

ZULETA, Mónica. (2006), “La violencia en Colombia: avatares de la construcción de un objeto de estudio". Revista Nómadas, n 25, pp. 54-69. 


\section{RESUMO}

Academia, Conflito Armadoe Paz na Colômbia: Uma Aproximação desde a Geopolitica do Conhecimento

Este artigo examina a geração de novo conhecimento sobre o conflito armado e a construção de paz na Colômbia, a partir da identificação dos aportes, debates e tendências da academia entre 1986 e 2018. Com base nos enfoques da geopolítica do conhecimento e a informação da plataforma ScienTI de Minciencias, explora-se a produção académica dos 5.202 grupos de pesquisa colombianos para estabelecer os avanços na compreensão da origem e a evolução da violência e os processos de reconciliação nacionais. Os resultados da análise mostram as forças e desafios na pesquisa nacional, dado que se evidencia uma continuidade limitada no trabalho dos grupos, assim como uma significativa centralização e a predominância de instituições e áreas de conhecimento.

Palavras-chave: conflito armado; Colômbia; geopolítica do conhecimento; pesquisa científica; violência

\section{RESUMEN}

Academia, Conflicto Armado y Paz en Colombia: Un Acercamiento desde la Geopolítica del Conocimiento

Este artículo examina la generación de nuevo conocimiento sobre el conflicto armado y la construcción de paz en Colombia, a partir de la identificación de los aportes, debates y tendencias de la academia entre 1986 y 2018. Con base en los enfoques de la geopolítica del conocimiento y la información de la plataforma ScienTI de Minciencias, se explora la producción académica de los 5.202 grupos de investigación colombianos para establecer los avances en la comprensión del origen y evolución de la violencia y los procesos de reconciliación nacionales. Los resultados del análisis revelan las fortalezas y retos en la investigación nacional, dado que se evidencia una continuidad limitada en el trabajo de los grupos, así como una significativa centralización y predominancia de instituciones y áreas de conocimiento.

Palabras clave: conflicto armado; Colombia; geopolítica del conocimiento; investigación científica; violencia 


\begin{abstract}
Academia, Armed Conflict, and Peace in Colombia: An Approach from the Geopolitics of Knowledge
\end{abstract}

This article examines the production of new knowledge about the armed conflict and the construction of peace in Colombia, based on the recognition of the contributions, debates and trends of Academia between 1986 and 2018. Based on approaches from the geopolitics of knowledge and information on the ScienTI-Minciencias platform, the academic production of the 5,202 Colombian research groups is explored to establish the progress in understanding the origin and evolution of violence and national reconciliation processes. The results of the analysis reveal the strengths and challenges in national research, given that there is limited continuity in the work of the groups, as well as a significant centralization and predominance of institutions and areas of knowledge.

Keywords: armed conflict; Colombia; geopolitics of knowledge; scientific investigation; violence

\title{
RÉSUMÉ
}

Universitaire, Conflit Aarmé et Paix en Colombie: Une Approche de la Géopolitique du Savoir

Cet article examine la production de nouvelles connaissances sur le conflit armé et la construction de la paix en Colombie, à partir de la reconnaissance des contributions, débats et tendances du milieu universitaire entre 1986 et 2018. Basé sur des approches de la Géopolitique des Connaissances et des informations sur la plateforme ScienTI-Minciencias, la production académique des 5202 groupes de recherche colombiens est explorée pour établir les progrès dans la compréhension de l'origine et de l'évolution des processus de violence et de réconciliation nationale. Les résultats de l'analyse révèlent les forces et les défis de la recherche nationale, étant donné que la continuité des travaux des groupes est limitée, ainsi qu'une centralisation et une prédominance importantes des institutions et des domaines de connaissances.

Mots-clés: conflit armé; Colombie; géopolitique de la connaissance; investigation scientifique; violence 